Bond University

Research Repository

\title{
Enteral and parenteral nutrition in cancer patients, a comparison of complication rates: an updated systematic review and (cumulative) meta-analysis
}

Chow, Ronald; Bruera, Eduardo; Arends, Jann; Walsh, Declan; Strasser, Florian; Isenring, Elisabeth; Del Fabbro, Egidio G.; Molassiotis, Alex; Krishnan, Monica; Chiu, Leonard; Chiu, Nicholas; Chan, Stephanie; Tang, Tian Yi; Lam, Henry; Lock, Michael; DeAngelis, Carlo Published in:

Supportive Care in Cancer

DOI:

10.1007/s00520-019-05145-w

Licence:

Other

Link to output in Bond University research repository.

Recommended citation(APA):

Chow, R., Bruera, E., Arends, J., Walsh, D., Strasser, F., Isenring, E., Del Fabbro, E. G., Molassiotis, A., Krishnan, M., Chiu, L., Chiu, N., Chan, S., Tang, T. Y., Lam, H., Lock, M., \& DeAngelis, C. (2020). Enteral and parenteral nutrition in cancer patients, a comparison of complication rates: an updated systematic review and (cumulative) meta-analysis. Supportive Care in Cancer, 28(3), 979-1010. https://doi.org/10.1007/s00520-01905145-w

\section{General rights}

Copyright and moral rights for the publications made accessible in the public portal are retained by the authors and/or other copyright owners and it is a condition of accessing publications that users recognise and abide by the legal requirements associated with these rights.

For more information, or if you believe that this document breaches copyright, please contact the Bond University research repository coordinator. 
March 25, 2019

\section{Enteral and parenteral nutrition in cancer patients, a comparison of complication rates: an updated systematic review and (cumulative) meta- analysis}

Ronald Chow ${ }^{1,2}$, Eduardo Bruera ${ }^{3}$, Jann Arends ${ }^{4}$, Declan Walsh ${ }^{5}$, Florian Strasser ${ }^{6}$, Elisabeth Isenring ${ }^{7}$, Egidio G Del Fabbro ${ }^{8}$, Alex Molassiotis ${ }^{9}$, Monica Krishnan ${ }^{10}$, Leonard Chiu ${ }^{1}$, Nicholas Chiu ${ }^{1}$, Stephanie Chan ${ }^{1}$, Tian Yi Tang ${ }^{2}$, Henry Lam ${ }^{1}$, Michael Lock ${ }^{2}$, Carlo DeAngelis ${ }^{1,11}$

${ }^{1}$ Sunnybrook Health Sciences Centre, University of Toronto, Toronto, ON, Canada

${ }^{2}$ London Health Sciences Centre, University of Western Ontario, London, ON, Canada

${ }^{3}$ University of Texas MD Anderson Cancer Centre, Houston, TX, United States of America

${ }^{4}$ University of Freiburg, Freiburg, Germany

${ }^{5}$ Levine Cancer Institute, Charlotte, NC, United States of America

${ }^{6}$ Cantonal Hospital, St. Gallen, Switzerland

${ }^{7}$ Bond University, Robina QLD 4226, Australia

${ }^{8}$ Virginia Commonwealth University Massey Cancer Centre, Richmond, VA, United States of America

${ }^{9}$ Hong Kong Polytechnic University, Hung Hom, Hong Kong SAR

${ }^{10}$ Dana-Farber Cancer Institute, Harvard Medical School, Boston, MA, United States of America

${ }^{11}$ Leslie Dan Faculty of Pharmacy, University of Toronto, Toronto, ON, Canada

Correspondence: Ronald Chow

London Health Sciences Centre, University of Western Ontario

800 Commissioners Road East, London, ON, Canada, N6A 5W9

rchow48@uwo.ca 
March 25, 2019

\begin{abstract}
Introduction

Weight loss in cancer patients is a worrisome constitutional change predicting disease progression and shortened survival time. A logical approach to counter some of the weight loss is to provide nutritional support, administered through enteral nutrition $(\mathrm{EN})$ or parenteral nutrition $(\mathrm{PN})$. The aim of this paper was to update the original systematic review and meta-analysis previously published by Chow et al, while also assessing publication quality and effect of RCTs on the metaconclusion over time.
\end{abstract}

\title{
Methods
}

A literature search was carried out; screening was conducted for randomized controlled trials published in January 2015 up until December 2018. The primary endpoints were the percentage of patients achieving no infection and no nutrition support complications. Secondary endpoints included proportion of patients achieving no major complications and no mortality. Review Manager (RevMan 5.3) by Cochrane IMS and Comprehensive Meta-Analysis (Version 3) by Biostat were used for meta-analyses of endpoints and assessment of publication quality.

\section{Results}

An additional 7 studies were identified since our prior publication, leading to 43 papers included in our review. The results echo those previously published; EN and PN are equivalent in all endpoints except for infection. Subgroup analyses of studies only containing adults indicate identical risks across all endpoints. Cumulative meta-analysis suggests that meta-conclusions have remained the same since the beginning of publication time for all endpoints except for the endpoint of infection, which changed from not favouring to favouring EN after studies published in 1997. There was low risk of bias, as determined by assessment tool and visual inspection of funnel plots. 
March 25, 2019

\section{Conclusions}

The results support the current European Society of Clinical Nutrition and Metabolism (ESPEN) guidelines recommending enteral over parenteral nutrition, when oral nutrition is inadequate, in adult patients. Further studies comparing EN and PN for these critical endpoints appear unnecessary, given the lack of change in meta-conclusion and low publication bias over the past decades.

Keywords: parenteral nutrition (PN), enteral nutrition (EN), cancer patients, malnutrition, tube feeding (TF), standard care (SC) 
March 25, 2019

\section{INTRODUCTION}

Unintentional weight loss for cancer patients is a worrisome constitutional change predicting disease progression and shortened survival time [1-2]. A logical approach to counter weight loss is to provide nutritional support, administered through enteral nutrition $(\mathrm{EN})$ or parenteral nutrition (PN) [3-4]. Historically, these approaches are accompanied with concerns of increased complications and costs; EN may hence be the preferred modality, due to its lower costs, fewer complications, and perceived better outcomes [4-6]. Over the past several decades, however, there have been substantial changes in clinical nutrition - the cost effectiveness of nutrition support has significantly increased through adoption of "all-in-one bags" for parenteral nutrition, novel enteral and parenteral formulas, peripheral insertion, and new materials for venous and enteral accesses, just to name a few [7]. New strategies, including standardized "bundles" of evidence-based interventions and strict policies of antisepsis, have also been developed and implemented to reduce the risk of complications [7].

The first meta-analysis comparing complication rates of EN and PN in cancer patients was published in 2016 [7], and looked at endpoints of infection, nutrition support complications, major complications and mortality. It included 36 articles [8-43], and reported that similar rates of nutrition support complications, major complications and mortality were observed between patients receiving EN and PN. Infection rates were reported to be slightly higher among PN patients.

Since the original review, more trials have been published and additional information has the potential for a more comprehensive meta-analysis with greater confidence in the principle conclusions. Moreover, the original review did not assess publication quality, or quantitatively assess for publication bias. With over 1,000 patients randomized to $\mathrm{EN}$ and $\mathrm{PN}$ each, the current 
meta-analysis may be sufficiently powered to offer a precise point estimate and recommend trial resources be dedicated elsewhere. To determine the effect of the latest randomized controlled trials (RCTs), a cumulative meta-analysis may adequately assess the meta-conclusion over time, as RCTs with new data are published.

The aim of this paper was to compare complication rates for EN and PN cancer patients, through updating the systematic review and meta-analysis previously published, while also assessing publication quality and effect of RCTs on the meta-conclusion over time.

\section{METHODS}

\section{Search Strategy}

A literature search was carried out in Ovid MEDLINE, Embase Classic and Embase, and Cochrane

Central Register of Controlled Trials. The search included studies up until the last week of December 2018 and was limited to English-language studies and RCTs. Search terms included "PN", "EN" and "comparative studies" [Appendix 1], similar to the prior review by Chow et al [7]. Reference lists of included studies were also included in the search.

\section{Selection Criteria}

Screening was conducted by two authors (RC, LC); where disagreement occurred, discussion and consensus was achieved with input from a third author (NC); Cohen's kappa coefficient documented the inter-rater agreement. Titles and abstracts published after January 2015 and beyond were screened and deemed relevant for full-text review if there was mention of parenteral nutrition and enteral nutrition, and additionally stated that the two nutrition support treatments 
were compared. Following full-text review, studies were included if over $50 \%$ of the study population had any form and any stage of cancer, in line with the prior review by Chow et al [7].

\section{Endpoints}

The primary endpoints were the percentage of patients achieving no infection and no nutrition support complications. Secondary endpoints included proportion of patients achieving no major complications and no mortality.

The definition of endpoints is the same as those reported by the former review published by Chow et al. [7]. Minor infections were recorded as reported in studies; when studies provided a breakdown of infection complications, the endpoint "minor infections" was the summation of wound infection, pneumonia and sepsis. Nutrition support complications were recorded as published in studies, or reported as the summation of nausea, vomiting and diarrhea events. Major complication events included major complications and morbidity are reported, as disclosed in studies. Mortality rate was noted as they were recorded in literature.

Additional study characteristics recorded include type of EN (standard care (SC) and tube feeding (TF)), nutrition status of population (including individuals who are malnourished or deemed with protein-energy malnutrition (PEM); studies not mentioning PEM were assumed to have no malnourished patients as we postulated that this demographic would be reported if PEM patients were prevalent) and age of population (children as defined by study, typically 21 years and younger, or adults).

\section{Statistical Analysis}


The Mantel-Haenszel model was applied and a random effects analysis model was used to generate risk ratios (RR) and their accompanying 95\% confidence intervals (CIs). A $p$-value of less than 0.05 was deemed statistically significant in the test for overall effect; a heterogeneity test with $p$ value greater than 0.05 was considered suitable. For all endpoints, we used the number of patients that did not experience the outcomes as the event numbers, to enable calculation of risks and risk ratios. Test for heterogeneity was conducted to determine whether the size of the effect was equal in all included studies. Review Manager (RevMan 5.3) by Cochrane IMS was used for the aforementioned analyses, to update the previously published analyses and forest plots. Comprehensive Meta-Analysis (Version 3) by Biostat was also used to conduct a cumulative metaanalysis, and assess the effect of studies to the meta-conclusion over publication time.

\section{Assessment of Publication Quality}

Funnel plots were generated by Review Manager (RevMan 5.3) to visually assess for publication bias. The Cochrane Risk of Bias assessment tool was employed to assess study quality of the included RCTs.

\section{RESULTS}

A total of 216 titles and abstracts were screened, of which 60 were identified for full-text screening $($ Cohen's kappa $=0.9239)$. The updated search yielded 7 additional studies [44-50] for inclusion in this systematic review and meta-analysis (Cohen's kappa $=0.7931)$ [Appendix 2]. The studies all reported on TF and studied adults. The study by Harvey et al. [46] included patients classified as PEM. 
March 25, 2019

\section{Infection}

PN was slightly statistically superior with respect to infection $(\mathrm{RR}=1.11 ; 95 \% \mathrm{CI}: 1.04-1.19)$. Subgroup analyses by EN indicated that TF is superior to $\mathrm{PN}$, whereas $\mathrm{SC}$ is equivalent. In patients suffering from PEM, PN and EN are equivalent. A higher risk of infection was noted among adult studies; no greater risk was reported among studies in children [Figure 1]. The aforementioned meta-conclusion, favouring PN, has remained unchanged since 1997; the cumulative RR remains in favour of PN with the inclusion of each published study dating to 1997 [Figure 2].

\section{Nutrition Support Complications}

Risk of nutrition support complications in $\mathrm{EN}$ and $\mathrm{PN}$ patients were equivalent $(\mathrm{RR}=1.00 ; 95 \%$ CI: 0.96-1.05). Subgroup analyses by modality of EN, nutrition status and age of population reveal that the rate of complications is equivalent within subgroups too [Figure 3]. Since the first study, the meta-conclusion has not favoured EN or PN [Figure 4].

\section{Major Complications}

Neither EN nor PN were superior with respect to lower incidence of major complications. No studies on children reported on this endpoint. Subgroup analyses of TF, SC, PEM studies and nonPEM studies reported a similar conclusion [Figure 5]. The meta-conclusion has remained the same since the first publications [Figure 6].

\section{Mortality}

Analyses and subgroup analyses indicate equivalent mortality rates between EN and PN [Figure 7]. The meta-conclusion over time has remained the same [Figure 8]. 
March 25, 2019

\section{Heterogeneity}

Unsuitable levels of heterogeneity were observed for all analyses of the endpoint "No infection", except for subgroup analyses of studies reporting on children [Figure 1]. Subgroup analyses of "No nutrition support complications" of subgroup SC, non-PEM studies, and child studies had appropriate levels of heterogeneity; other analyses of this endpoint have unsuitable levels [Figure 3]. These unsatisfactory levels may be a consequence of different clinical methodologies, such as different definitions of endpoints across different studies. All analyses of "No major complications" except for subgroup analyses of SC had satisfactory heterogeneity [Figure 5]. Satisfactory levels were observed for all analyses of endpoint "No mortality" [Figure 7].

\section{Publication Quality}

The majority of studies had low risk of bias [Appendix 3]. No obvious publication biases exist, as noted by lack of glaring asymmetries upon visual inspection of funnel plots [Appendices 4-7].

\section{DISCUSSION}

This systematic review and meta-analysis comparing complication rates between cancer patients administered EN or PN includes 43 studies, which is the highest-powered analysis to date in the cancer setting: the original meta-analysis by Chow et al. in 2016 comprised of 36 studies, while Braunschweig et al.'s study in 2001 had only 7 studies in their subgroup analyses of cancer patients [51]. The results in this study echo those published in 2016; EN and PN are equivalent in all endpoints except for infection [7]. In fact, cumulative meta-analysis suggests that metaconclusions have remained the same since the beginning of publication time (i.e. the first published 
March 25, 2019

RCT) for all endpoints except for the endpoint of infection, which changed from not favouring to favouring EN after studies published in 1997.

Compared to the original review, this review involved additional analyses. The prior review conducted subgroup analyses only by type of $\mathrm{EN}$ and nutrition status; this review also investigated endpoints by age of the study population. For studies containing children, PN was equivalent to EN in all three endpoints - infection, nutrition support complications, and mortality; no studies reported on major complications/morbidity. In adults, the conclusion remains unchanged: EN is superior to PN only in infection. These results hence support the current European Society of Clinical Nutrition and Metabolism (ESPEN) guidelines that suggests enteral over parenteral where the gastrointestinal tract works, when oral nutrition is inadequate [52].

Lack of bias, as assessed by the Cochrane Risk of Bias assessment tool and through visual inspection of funnel plots, suggests that the existing literature appropriately documents critical endpoints of PN compared to EN; RCTs, in line with the nature of their study type, did not have critical methodology flaws/biases. This, when considered in conjunction with the results of the cumulative meta-analyses examining studies over the past two decades has only refined our point estimate and has not altered our meta-conclusion, suggests that no new trials are required in this setting to look into these critical endpoints. When considering whether a cancer patient should be administered EN or PN, other considerations should be pondered.

PN has been reported to require less time in improving a patient's nutritional state, which can minimize hospital stays and help expedite turnover of hospital beds to care for more patients [43]. However, EN is nearly half the cost of PN, and may be more fiscally favourable [20]. PN has also been reported to be more beneficial for cancer surgery patients; PN may continue uninterrupted during settings where oral feeding may need to be withheld, such as during some 
preoperative diagnostic procedures [13]. However, the results of this meta-analysis suggest that risk of major complications/morbidity and mortality of both nutrition support routes are still equivalent.

This review has its limitations. The reporting of endpoints across studies was not standardized: different definitions and recording methods for infections, nutrition support complications, and major complication outcomes existed. To accurately capture and extract endpoints, we reviewed and contacted corresponding authors when necessary for clarification of endpoints and collection of more data. Overall risk ratios computed by cumulative meta-analyses and standard meta-analysis forest plots differed slightly, due to rounding. Assessment of publication bias via funnel plots did not include accompanying quantitative metrics such as Egger's test; the lack of asymmetry, however, clearly indicates no publication bias.

This systematic review reaffirms the conclusions originally reported by the meta-analysis by Chow et al: that neither PN nor EN are superior for all endpoints (major complications, mortality, nutrition support complications) other than infection. Cumulative meta-analyses, in fact, indicate that the meta-conclusion has not changed for several decades; new trials investigating these endpoints are likely unnecessary as they would add little value to the existing body of literature. Subgroup analyses of studies only containing adult patients show no superiority of PN compared to EN, supporting ESPEN's latest guidelines recommending EN should be provided for cancer patients where oral intake is inadequate or they are already malnourished, given that their gastrointestinal tract is functional.

\section{REFERENCES}


1. Dewys WD, Begg C, Lavin PT et al. Prognostic effect of weight loss prior to chemotherapy in cancer patients. Eastern Cooperative Oncology Group. Am J Med 1980; 69: 491-7.

2. Stanley KE. Prognostic factors for survival in patients with inoperable lung cancer. J Natl Cancer Inst 1980; 65: 25-32.

3. Klein S, Koretz RL. Nutrition support in patients with cancer: what do the data really show? Nutr Clin Pract 1994; 9: 91-100.

4. Altintas ND, Aydin K, Turkoglu MA et al. Effect of enteral versus parenteral nutrition on outcome of medical patients requiring mechanical ventilation. Nutr Clin Pract 2011; 26: $322-9$

5. Mullen JL. Complications of total parenteral nutrition in the cancer patient. Cancer Treat Rep 1981; 65 Suppl 5: 107-13.

6. Twomey PL, Patching SC. Cost-effectiveness of nutritional support. JPEN J Parenter Enteral Nutr 1985; 9: 3-10.

7. Chow R, Bruera E, Chiu L et al. Enteral and parenteral nutrition in cancer patients: a systematic review and meta-analysis. Ann Palliat Med 2016; 5(1): 30-41.

8. Holter AR, Fischer JE. The effects of perioperative hyperalimentation on complications in patients with carcinoma and weight loss. J Surg Res 1977; 23: 31-4.

9. van Eys J, Copeland EM, Cangir A et al. A clinical trial of hyperalimentation in children with metastatic malignancies. Med Pediatr Oncol 1980; 8: 63-73.

10. Thompson BR, Julian TB, Strmple JF. Perioperative total parenteral nutrition in patients with gastrointestinal cancer. J Surg Res 1981; 30: 497-500. 
11. Sako K, Lore JM, Kaufman $\mathrm{S}$ et al. Parenteral hyperalimentation in surgical hyperalimentation in surgical patients with head and neck cancer: a randomized study. J Surg Oncol 1981; 16: 391-402.

12. Lim ST, Choa RG, Lam KH et al. Total parenteral nutrition versus gastrostomy in the preoperative preparation of patients with carcinoma of the oesophagus. Br J Surg 1981; 68: $69-72$.

13. Muller JM, Brenner U, Dienst C et al. Preoperative parenteral feeding in patients with gastrointestinal carcinoma. Lancet 1981; 1: 68-71.

14. van Eys J, Wesley MN, Cangir A et al. Safety of intravenous hyperalimentation in children with malignancies: a cooperative group trial. JPEN J Parenter Enteral Nutr 1982; 6: 291-4.

15. Ghavimi F, Shils ME, Scott BF et al. Comparison of morbidity in children requiring abdominal radiation and chemotherapy, with and without total parenteral nutrition. $\mathrm{J}$ Pediatr 1982; 101: 530-7.

16. Donaldson SS, Wesley MN, Ghavimi F et al. A prospective randomized clinical trial of total parenteral nutrition in children with cancer. Med Pediatr Oncol 1982; 10: 129-39.

17. Hays DM, Merritt RJ, White L et al. Effect of total parenteral nutrition on marrow recovery during induction therapy for acute nonlymphocytic leukemia in childhood. Med Pediatr Oncol 1983; 11: 134-40.

18. Rickard KA, Detamore CM, Coates TD et al. Effect of nutrition staging on treatment delays and outcome in Stage IV neuroblastoma. Cancer 1983; 52: 587-98.

19. Heylen AM, Lybeer MB, Penninckx FM et al. Parenteral versus needle jejunostomy nutrition after total gastrectomy. Clin Nutr 1987; 6: 131-6. 
March 25, 2019

20. Hamaoui E, Lefkowitz R, Olender L et al. Enteral nutrition in the early postoperative period: a new semi-elemental formula versus total parenteral nutrition. JPEN J Parenter Enteral Nutr 1990; 14: 501-7.

21. Von Meyenfeldt MF, Meijerink WJ, Rouflart MM et al. Perioperative nutritional support: a randomised clinical trial. Clin Nutr 1992; 11: 180-6.

22. Smith DE, Handy DJ, Holden CE et al. An investigation of supplementary nasogastric feeding in malnourished children undergoing treatment for malignancy: results of a pilot study. J Hum Nutr Diet 1992; 5: 85-91.

23. Sandstrom R, Drott C, Hyltander A et al. The effect of postoperative intravenous feeding (TPN) on outcome following major surgery evaluated in a randomized study. Ann Surg 1993; 217: 185-95.

24. Iovinelli G, Marsili I, Varrassi G. Nutrition support after total laryngectomy. JPEN J Parenter Enteral Nutr 1993; 17: 445-8.

25. Brennan MF, Pisters PW, Posner M et al. A prospective randomized trial of total parenteral nutrition after major pancreatic resection for malignancy. Ann Surg 1994; 220: 436-41.

26. Shirabe K, Matsumata T, Shimada M et al. A comparison of parenteral hyperalimentation and early enteral feeding regarding systemic immunity after major hepatic resection - the results of a randomized prospective study. Hepatogastroenterology 1997; 44: 205-9.

27. Sand J, Luostarinen M, Matikainen M. Enteral or parenteral feeding after total gastrectomy: prospective randomised pilot study. Eur J Surg 1997; 163: 761-6.

28. Reynolds JV, Kanwar S, Welsch FK et al. 1997 Harry M Vars Research Award. Does the route of feeding modify gut barrier function and clinical outcome in patients after major upper gastrointestinal surgery? JPEN J Parenter Enteral Nutr 1997; 21: 196-201. 
29. Bozzetti F, Braga M, Gianotti L et al. Postoperative enteral versus parenteral nutrition in malnourished patients with gastrointestinal cancer: a randomised multicentre trial. Lancet 2001; 358: 1487-92.

30. Pacelli F, Bossola M, Papa V et al. Enteral vs parenteral nutrition after major abdominal surgery: an even match. Arch Surg 2001; 136: 933-6.

31. Aiko S, Yoshizumi Y, Maysuyama T et al. Influences of thoracic duct blockage on early enteral nutrition for patients who underwent esophageal cancer surgery. Jpn J Thorac Cardiovasc Surg 2003; 51:263-71.

32. Jiang XH, Li N, Li JS. Intestinal permeability in patients after surgical trauma and effect of enteral nutrition versus parenteral nutrition. World J Gastroenterol 2003; 9: 1878-80.

33. Kamei H, Hachisuka T, Nakao M et al. Quick recovery of serum diamine oxidase activity in patients undergoing total gastrectomy by oral enteral nutrition. Am J Surg 2005; 189: $38-43$.

34. Hyltander A, Bosaeus I, Svedlund J et al. Supportive nutrition on recovery of metabolism, nutritional state, health-related quality of life and exercise capacity after major surgery: a randomized study. Clin Gastroenterol Hepatol 2005; 3: 466-74.

35. Schmid I, Schmitt M, Streiter M et al. Parenteral nutrition is not superior to replacement fluid therapy for the supportive treatment of chemotherapy induced oral mucositis in children. Eur J Cancer 2006; 42: 205-11.

36. Seike J, Tangoku A, Yuasa Y et al. The effect of nutritional support on the immune function in the acute postoperative period after esophageal cancer surgery: total parenteral nutrition versus enteral nutrition. J Med Invest 2011; 58: 75-80. 
March 25, 2019

37. Liu C, Du Z, Lou C et al. Enteral nutrition is superior to total parenteral nutrition for pancreatic cancer patients who underwent pancreaticoduodenectomy. Asia Pac J Clin Nutr 2011; 20: 154-60.

38. Park JS, Chung HK, Hwang HK et al. Postoperative nutritional effects of early enteral feeding compared with total parenteral nutrition in pancreaticoduodectomy patients: a prospective, randomized study. J Korean Med Sci 2012; 27: 261-7.

39. Li G, Gu R, Wen X et al. The effect of early enteral nutrition on hyperthermic intraoperative intraperitoneal chemotherapy-induced mucosal permeability following gastrectomy. JPEN J Parenter Enteral Nutr 2012; 36: 213-8.

40. Fujita T, Daiko H, Nishimura H. Early enteral nutrition reduces the rate of life-threatening complications after thoracic esophagectomy in patients with esophageal cancer. Eur Surg Res 2012; 48: 79-84.

41. Boelens PG, Heesakkers FF, Luyer MD et al. Reduction of postoperative ileus by early enteral nutrition in patients undergoing major rectal surgery: prospective, randomized, controlled trial. Ann Surg 2014; 259: 649-655.

42. Klek S, Szybinski P, Szczepanek K. Perioperative immunonutrition in surgical cancer patients: a summary of a decade of research. World J Surg 2014; 38: 803-12.

43. Dmytriiev D, Katilov O, Dmytriiev K et al. The role of perioperative enteral and parenteral nutrition treatment in children with abdominal cancer. Clin Nutr 2014; 33: S134-5.

44. Li B, Liu HY, Guo SH et al. Impact of early enteral and parenteral nutrition on prealbumin and high-sensitivity C-reactive protein after gastric surgery. Genetics and Molecular Research 2015; 14: 7130-5. 
45. Huang D, Sun Z, Huang J et al. Early enteral nutrition in combination with parenteral nutrition in elderly patients after surgery due to gastrointestinal cancer. Int J Clin Exp Med $2015 ; 8: 13937-45$.

46. Harvey SE, Parrott F, Harrison DA et al. A multicentre, randomised controlled trial comparing the clinical effectiveness and cost-effectiveness of early nutritional support via the parenteral versus the enteral route in critically ill patients (CALORIES). Health Technol Assess 2016; 20.

47. Perinel J, Mariette C, Dousset B et al. Early enteral versus total parenteral nutrition in patients undergoing pancreaticoduodenectomy. Ann Surg 2016; 264: 731-7.

48. Chen ZH, Lin SY, Dai QB et al. The effects of pre-operative enteral nutrition from nasal feeding tubes on gastric outlet obstruction. Nutrients 2017; 9: 373.

49. Luo Z, Wang J, Zhang Z et al. Efficacy of early enteral immunonutrition on immune function and clinical outcome for postoperative patients with gastrointestinal cancer. JPEN J Parenter Enteral Nutr 2018; 42: 758-65.

50. Wang J, Zhao J, Zhang Y et al. Early enteral nutrition and total parenteral nutrition on the nutritional status and blood glucose in patients with gastric cancer complicated with diabetes mellitus after radical gastrectomy. Experimental and Therapeutic Medicine 2018; 16: $321-7$.

51. Braunschweig CL, Levy P, Sheean PM et al. Enteral compared with parenteral nutrition: a meta-analysis. Am J Clin Nutr 201; 74: 534-42.

52. Arends J, Bachmann P, Baracos V et al. ESPEN guidelines on nutrition in cancer patients. Clin Nutr 2017; 36: 11-48. 
March 25, 2019

Figure 1.1

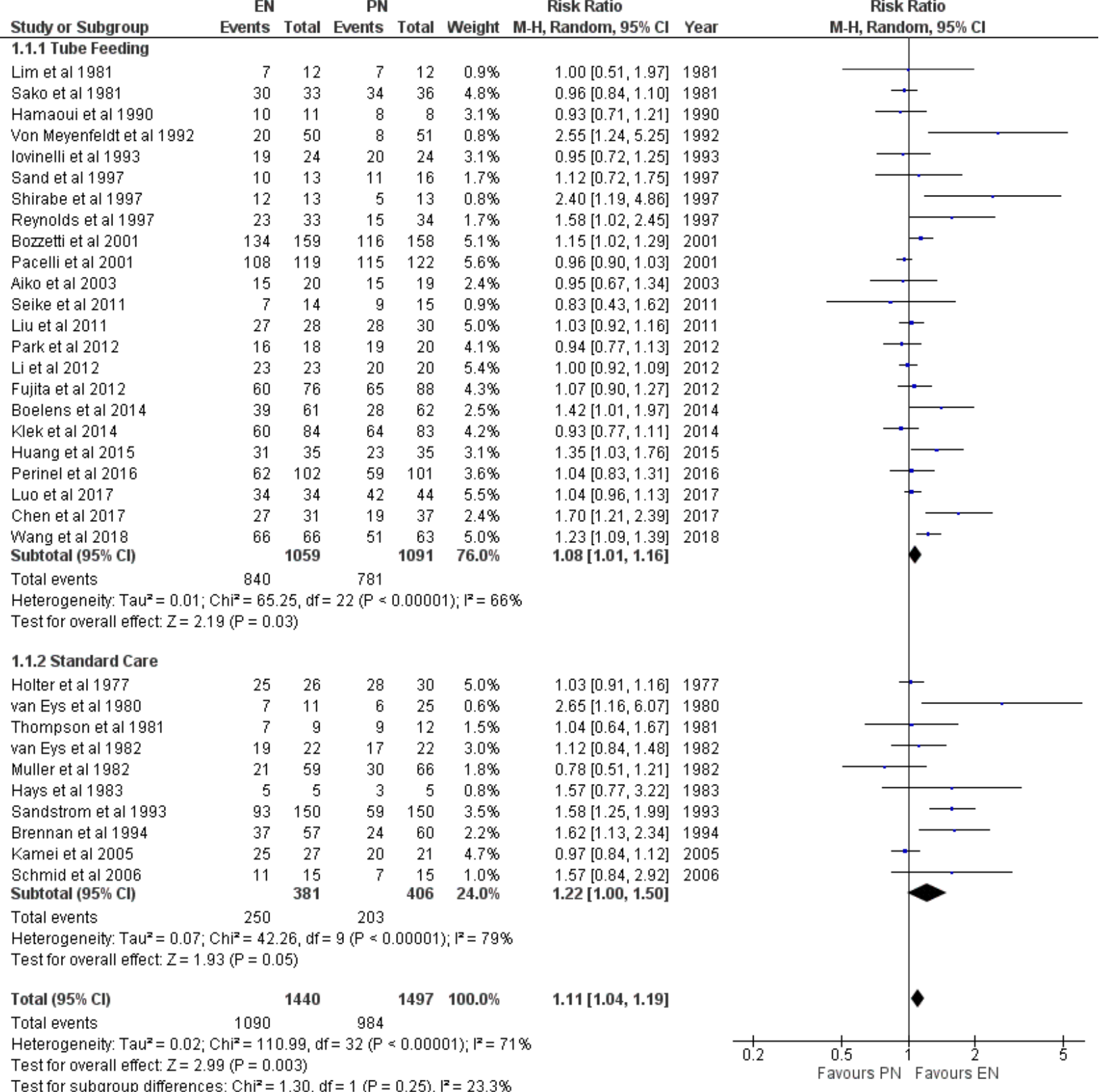

This is a post-peer-review, pre-copyedit version of an article published in Supportive Care in Cancer.

The final authenticated version is available online at: https://doi.org/10.1007/s00520-019-05145-w 
March 25, 2019

\section{Figure 1.2}

\begin{tabular}{|c|c|c|c|c|c|c|c|}
\hline & EN & & PN & & & Risk Ratio & \\
\hline Study or Subgroup & Events & Total & Events & Total & Weight & M-H, Random, 95\% Cl & \\
\hline 1.2.1 PEM & & & & & & & \\
\hline Holter et al 1977 & 25 & 26 & 28 & 30 & $5.0 \%$ & $1.03[0.91,1.16]$ & \\
\hline van Eys et al 1980 & 7 & 11 & 6 & 25 & $0.6 \%$ & $2.65[1.16,6.07]$ & \\
\hline Lim et al 1981 & 7 & 12 & 7 & 12 & $0.9 \%$ & $1.00[0.51,1.97]$ & \\
\hline Sako et al 1981 & 30 & 33 & 34 & 36 & $4.8 \%$ & $0.96[0.84,1.10]$ & \\
\hline Thompson et al 1981 & 7 & 9 & 9 & 12 & $1.5 \%$ & $1.04[0.64,1.67]$ & \\
\hline Muller et al 1982 & 21 & 59 & 30 & 66 & $1.8 \%$ & $0.78[0.51,1.21]$ & \\
\hline van Eys et al 1982 & 19 & 22 & 17 & 22 & $3.0 \%$ & $1.12[0.84,1.48]$ & \\
\hline Von Meyenfeldt et al 1992 & 20 & 50 & 8 & 51 & $0.8 \%$ & $2.55[1.24,5.25]$ & \\
\hline Sandstrom et al 1993 & 93 & 150 & 59 & 150 & $3.5 \%$ & $1.58[1.25,1.99]$ & \\
\hline Reynolds et al 1997 & 23 & 33 & 15 & 34 & $1.7 \%$ & $1.58[1.02,2.45]$ & \\
\hline Bozzetti et al 2001 & 134 & 159 & 116 & 158 & $5.1 \%$ & $1.15[1.02,1.29]$ & \\
\hline Park et al 2012 & 16 & 18 & 19 & 20 & $4.1 \%$ & $0.94[0.77,1.13]$ & \\
\hline Klek et al 2014 & 60 & 84 & 64 & 83 & $4.2 \%$ & $0.93[0.77,1.11]$ & \\
\hline Subtotal $(95 \% \mathrm{Cl})$ & & 666 & & 699 & $36.9 \%$ & $1.12[0.98,1.28]$ & \\
\hline Total events & 462 & & 412 & & & & \\
\hline $\begin{array}{l}\text { Heterogeneity: } \operatorname{Tau}^{2}=0.0 \\
\text { Test for overall effect: } Z=\end{array}$ & $\begin{array}{l}\mathrm{hi}^{2}=43 \\
(\mathrm{P}=0 .\end{array}$ & 97 , d & $2(\mathrm{P}<$ & 000 & $\left.\right|^{2}=7$ & & \\
\hline 1.2.2 No PEM & & & & & & & \\
\hline Hays et al 1983 & 5 & 5 & 3 & 5 & $0.8 \%$ & $1.57[0.77,3.22]$ & \\
\hline Hamaoui et al 1990 & 10 & 11 & 8 & 8 & $3.1 \%$ & $0.93[0.71,1.21]$ & \\
\hline lovinelli et al 1993 & 19 & 24 & 20 & 24 & $3.1 \%$ & $0.95[0.72,1.25]$ & \\
\hline Brennan et al 1994 & 37 & 57 & 24 & 60 & $2.2 \%$ & $1.62[1.13,2.34]$ & \\
\hline Shirabe et al 1997 & 12 & 13 & 5 & 13 & $0.8 \%$ & $2.40[1.19,4.86]$ & \\
\hline Sand et al 1997 & 10 & 13 & 11 & 16 & $1.7 \%$ & $1.12[0.72,1.75]$ & \\
\hline Pacelli et al 2001 & 108 & 119 & 115 & 122 & $5.6 \%$ & $0.96[0.90,1.03]$ & \\
\hline Aiko et al 2003 & 15 & 20 & 15 & 19 & $2.4 \%$ & $0.95[0.67,1.34]$ & \\
\hline Kamei et al 2005 & 25 & 27 & 20 & 21 & $4.7 \%$ & $0.97[0.84,1.12]$ & \\
\hline Schmid et al 2006 & 11 & 15 & 7 & 15 & $1.0 \%$ & $1.57[0.84,2.92]$ & \\
\hline Liu et al 2011 & 27 & 28 & 28 & 30 & $5.0 \%$ & $1.03[0.92,1.16]$ & \\
\hline Seike et al 2011 & 7 & 14 & 9 & 15 & $0.9 \%$ & $0.83[0.43,1.62]$ & \\
\hline Li et al 2012 & 23 & 23 & 20 & 20 & $5.4 \%$ & $1.00[0.92,1.09]$ & \\
\hline Fujita et al 2012 & 60 & 76 & 65 & 88 & $4.3 \%$ & $1.07[0.90,1.27]$ & \\
\hline Boelens et al 2014 & 39 & 61 & 28 & 62 & $2.5 \%$ & $1.42[1.01,1.97]$ & \\
\hline Huang et al 2015 & 31 & 35 & 23 & 35 & $3.1 \%$ & $1.35[1.03,1.76]$ & \\
\hline Perinel et al 2016 & 62 & 102 & 59 & 101 & $3.6 \%$ & $1.04[0.83,1.31]$ & \\
\hline Luo et al 2017 & 34 & 34 & 42 & 44 & $5.5 \%$ & $1.04[0.96,1.13]$ & \\
\hline Chen et al 2017 & 27 & 31 & 19 & 37 & $2.4 \%$ & $1.70[1.21,2.39]$ & \\
\hline Wang et al 2018 & 66 & 66 & 51 & 63 & $5.0 \%$ & $1.23[1.09,1.39]$ & \\
\hline Subtotal $(95 \% \mathrm{CI})$ & & 774 & & 798 & $63.1 \%$ & $1.11[1.02,1.20]$ & \\
\hline
\end{tabular}

Total events 572

Heterogeneity: $\mathrm{Tau}^{2}=0.02 ; \mathrm{Chi}^{2}=63.19, \mathrm{df}=19(\mathrm{P}<0.00001) ; \mathrm{I}^{2}=70 \%$

Test for overall effect: $Z=2.46(P=0.01)$

Total $(95 \% \mathrm{Cl})$

1440

$1497100.0 \%$

$1.11[1.04,1.19]$

Total events 1090 984

Heterogeneity: Tau $^{2}=0.02 ; \mathrm{Chi}^{2}=110.99, \mathrm{df}=32(\mathrm{P}=0.00001) ; \mathrm{I}^{2}=71 \%$

Test for overall effect: $Z=2.99(P=0.003)$

Test for subqroup differences: $\mathrm{Chi}^{2}=0.02, \mathrm{df}=1(\mathrm{P}=0.89), \mathrm{I}^{2}=0 \%$

Risk Ratio

M-H, Random, 95\% Cl

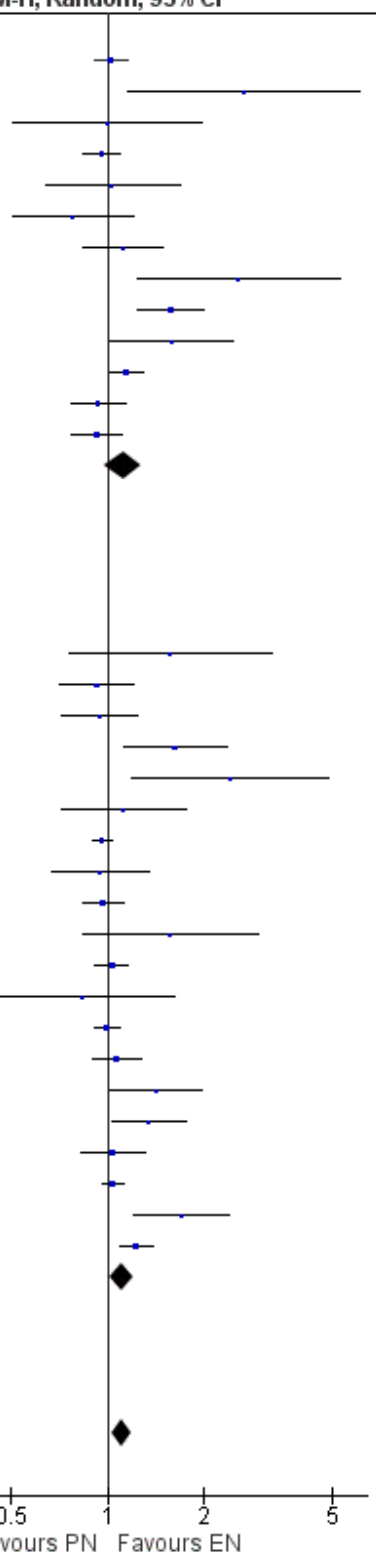

This is a post-peer-review, pre-copyedit version of an article published in Supportive Care in Cancer.

The final authenticated version is available online at: https://doi.org/10.1007/s00520-019-05145-w 
March 25, 2019

\section{Figure 1.3}

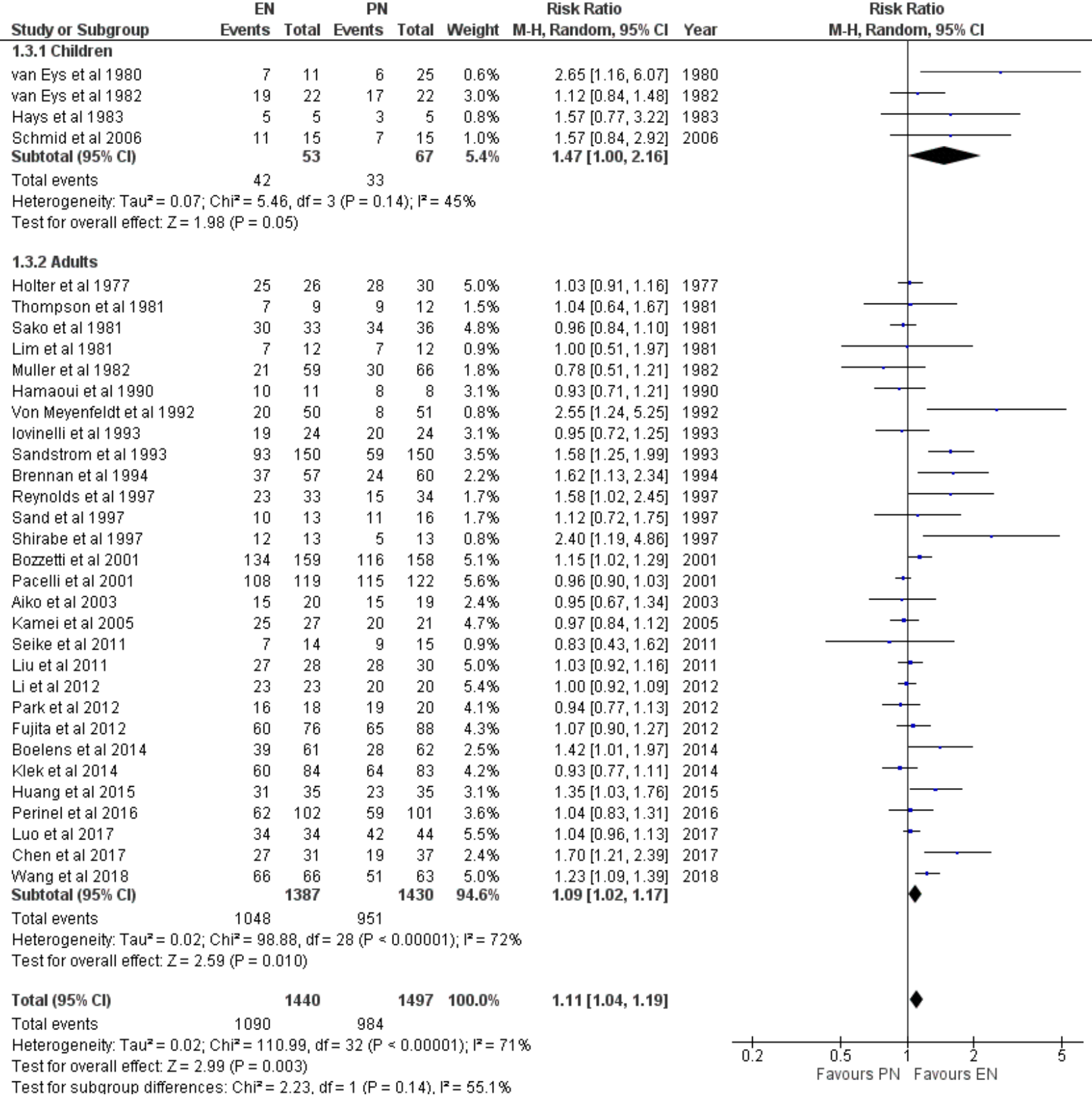

Figure 1. No infection for enteral nutrition (EN) and parenteral nutrition (PN) patients 1.1 Analyses by EN - tube feeding and standard care 1.2 Analyses by nutrition status - protein energy malnutrition (PEM) and no PEM 1.3 Analyses by age of population - children and adults

This is a post-peer-review, pre-copyedit version of an article published in Supportive Care in Cancer.

The final authenticated version is available online at: https://doi.org/10.1007/s00520-019-05145-w 
March 25, 2019

Study name

$\begin{array}{lcccrr} & \text { Point } & \begin{array}{c}\text { Lower } \\ \text { limit }\end{array} & \begin{array}{c}\text { Upper } \\ \text { limit }\end{array} & \text { Z-Value } & \text { p-Value } \\ \text { Holter et al 1977 } & 1.030 & 0.754 & 1.407 & 0.187 & 0.851 \\ \text { van Eys et al 1980 } & 1.145 & 0.854 & 1.536 & 0.907 & 0.365 \\ \text { Thompson et al 1981 } & 1.121 & 0.865 & 1.453 & 0.862 & 0.389 \\ \text { Sako et al 1981 } & 1.054 & 0.863 & 1.288 & 0.516 & 0.606 \\ \text { Lim et al 1981 } & 1.050 & 0.866 & 1.275 & 0.498 & 0.619 \\ \text { Muller et al 1982 } & 1.013 & 0.845 & 1.215 & 0.144 & 0.886 \\ \text { van Eys et al 1982 } & 1.030 & 0.873 & 1.216 & 0.355 & 0.723 \\ \text { Hays et al 1983 } & 1.050 & 0.893 & 1.234 & 0.587 & 0.557 \\ \text { Hamaoui et al 1990 } & 1.031 & 0.888 & 1.197 & 0.396 & 0.692 \\ \text { Von Meyenfeldt et al 1992 } 1.065 & 0.919 & 1.233 & 0.836 & 0.403 \\ \text { Sandstrom et al 1993 } & 1.123 & 0.980 & 1.287 & 1.664 & 0.096 \\ \text { Iovinelli et al 1993 } & 1.103 & 0.970 & 1.255 & 1.490 & 0.136 \\ \text { Brennan et al 1994 } & 1.134 & 1.002 & 1.284 & 1.984 & 0.047 \\ \text { Shirabe et al 1997 } & 1.156 & 1.023 & 1.307 & 2.322 & 0.020 \\ \text { Sand et al 1997 } & 1.154 & 1.024 & 1.301 & 2.356 & 0.018 \\ \text { Reynolds et al 1997 } & 1.172 & 1.043 & 1.317 & 2.675 & 0.007 \\ \text { Bozzetti et al 2001 } & 1.169 & 1.049 & 1.304 & 2.812 & 0.005 \\ \text { Pacelli et al 2001 } & 1.142 & 1.031 & 1.265 & 2.551 & 0.011 \\ \text { Aiko et al 2003 } & 1.132 & 1.025 & 1.250 & 2.437 & 0.015 \\ \text { Kamei et al 2005 } & 1.117 & 1.015 & 1.228 & 2.276 & 0.023 \\ \text { Schmid et al 2006 } & 1.124 & 1.023 & 1.235 & 2.433 & 0.015 \\ \text { Seike et al 2011 } & 1.118 & 1.019 & 1.228 & 2.349 & 0.019 \\ \text { Liu et al 2011 } & 1.111 & 1.016 & 1.215 & 2.309 & 0.021 \\ \text { Park et al 2012 } & 1.099 & 1.008 & 1.199 & 2.140 & 0.032 \\ \text { Fujita et al 2012 } & 1.097 & 1.009 & 1.193 & 2.169 & 0.030 \\ \text { Boelens et al 2014 } & 1.107 & 1.020 & 1.202 & 2.422 & 0.015 \\ \text { Klek et al 2014 } & 1.096 & 1.012 & 1.187 & 2.248 & 0.025 \\ \text { Huang et al 2015 } & 1.105 & 1.022 & 1.195 & 2.501 & 0.012 \\ \text { Perinel et al 2016 } & 1.102 & 1.021 & 1.190 & 2.490 & 0.013 \\ \text { Luo et al 2017 } & 1.099 & 1.020 & 1.183 & 2.482 & 0.013 \\ \text { Chen et al 2017 } & 1.111 & 1.033 & 1.196 & 2.830 & 0.005 \\ \text { Wang et al 2018 } & 1.118 & 1.041 & 1.200 & 3.057 & 0.002 \\ & 1.118 & 1.041 & 1.200 & 3.057 & 0.002 \\ & & & & & \\ & & & & \\ & & & \end{array}$

Cumulative mh risk ratio $(95 \% \mathrm{CI})$

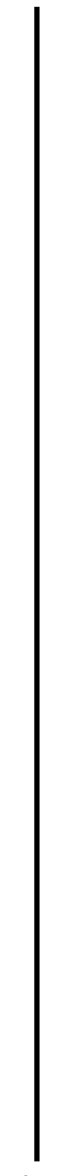

0.5

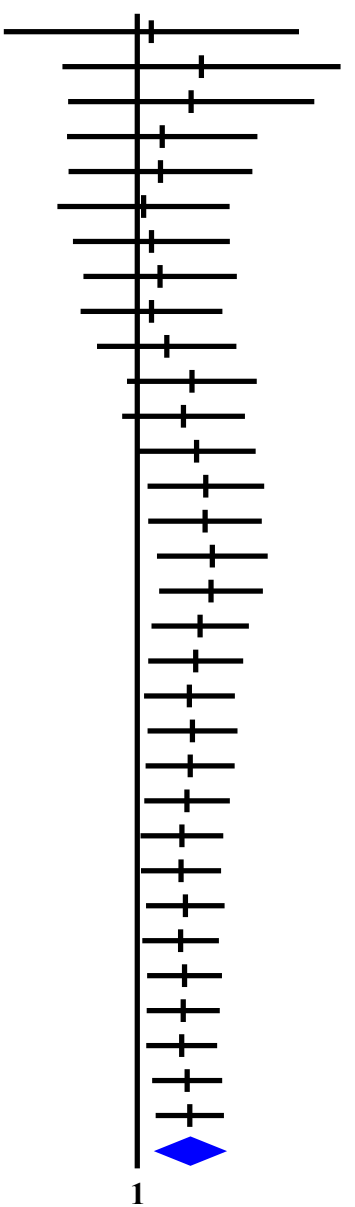

Favours EN

Figure 2. No infection for enteral $(\mathrm{EN})$ and parenteral nutrition $(\mathrm{PN})$ patients, over time 
March 25, 2019

Figure 3.1

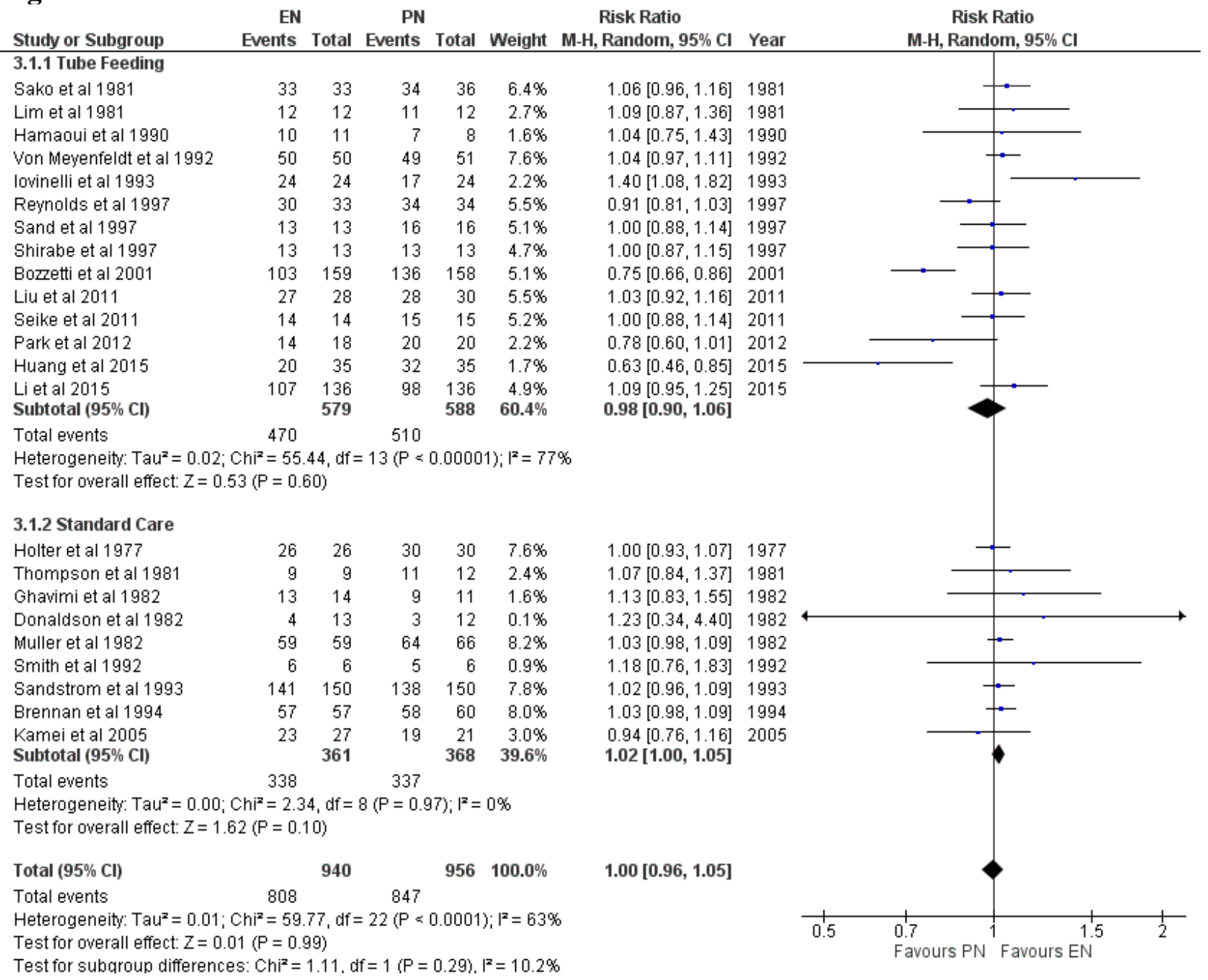

This is a post-peer-review, pre-copyedit version of an article published in Supportive Care in Cancer. The final authenticated version is available online at: https://doi.org/10.1007/s00520-019-05145-w 
March 25, 2019

\section{Figure 3.2}

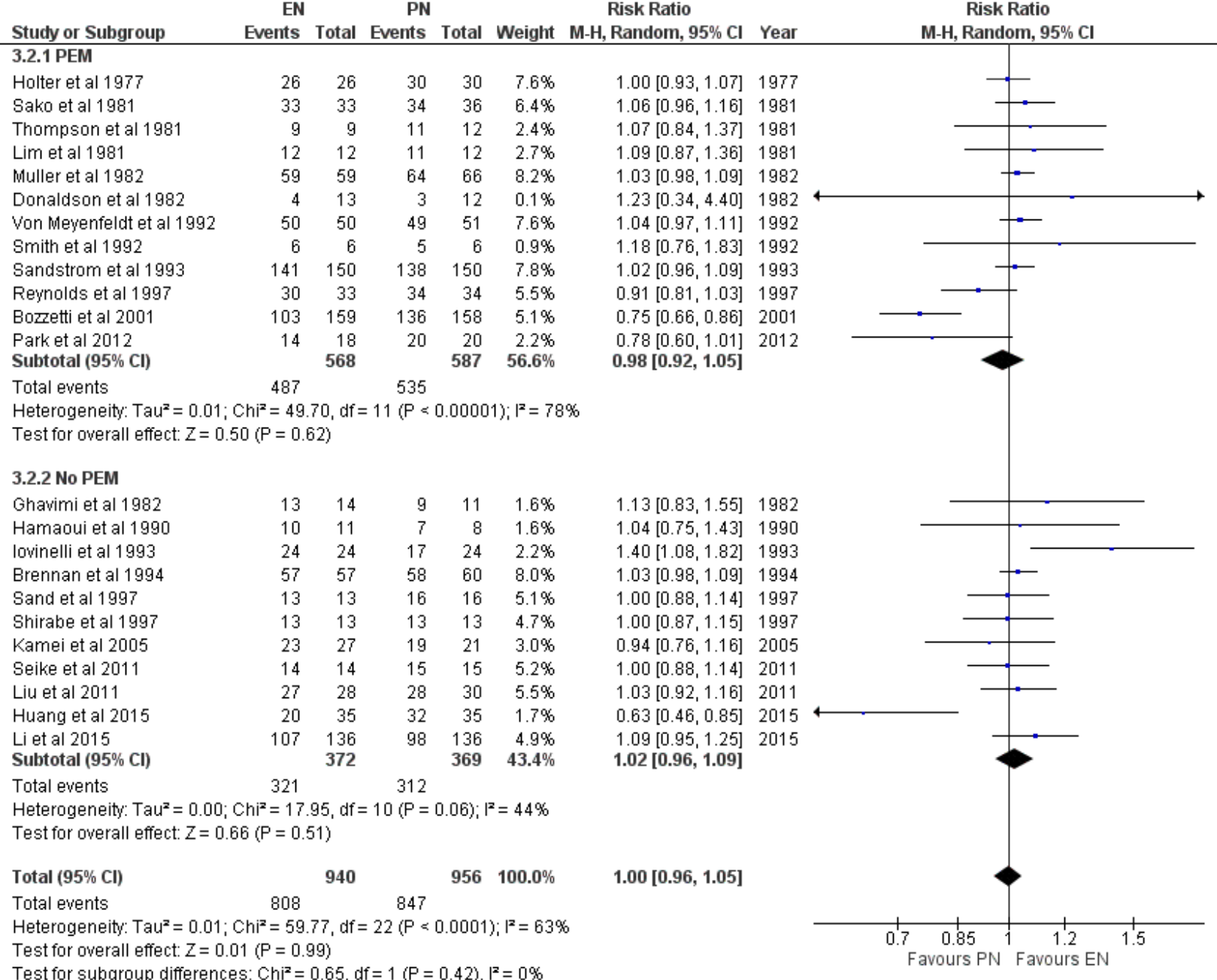

This is a post-peer-review, pre-copyedit version of an article published in Supportive Care in Cancer. The final authenticated version is available online at: https://doi.org/10.1007/s00520-019-05145-w 
March 25, 2019

\section{Figure 3.3}

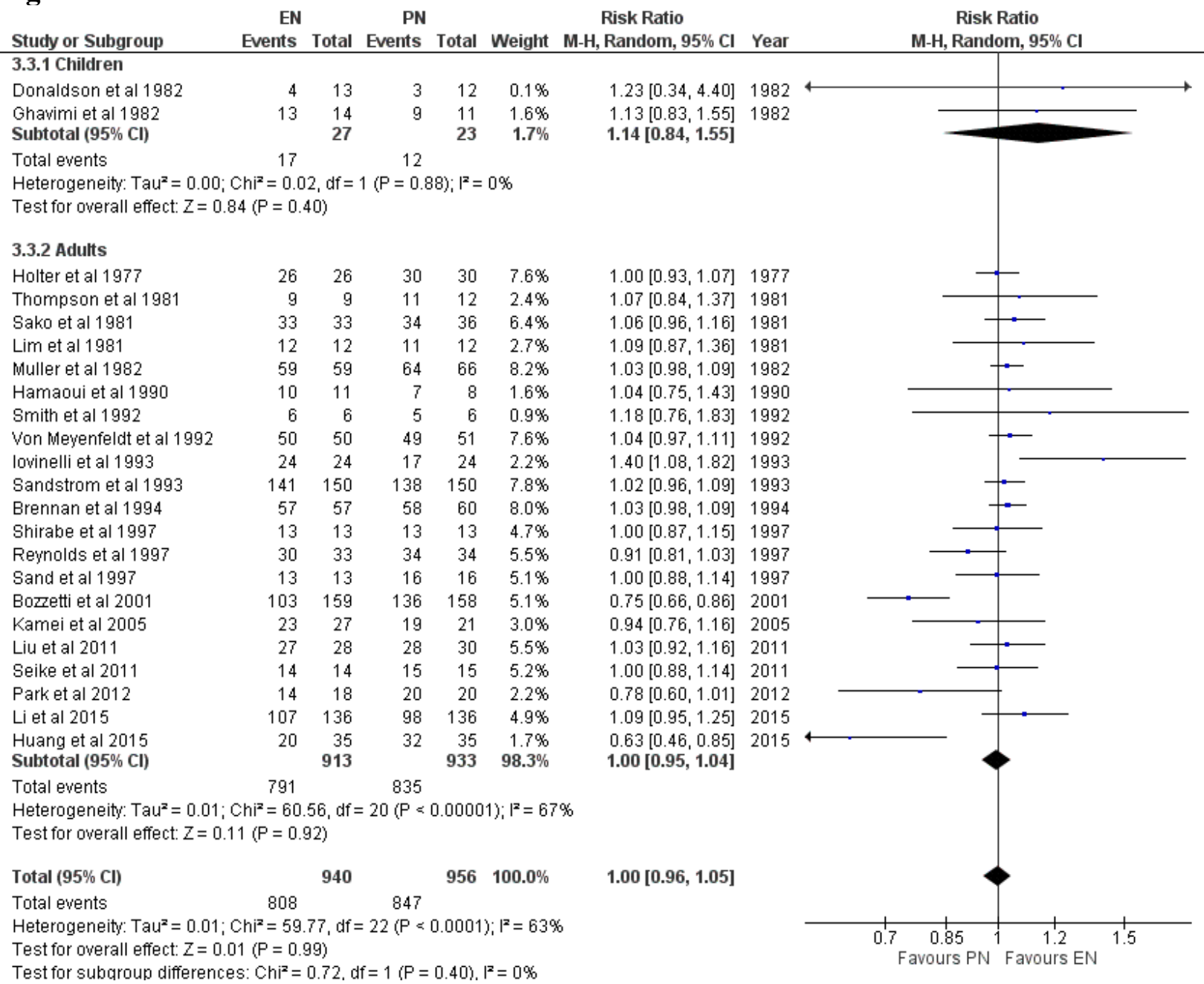

Figure 3. No nutrition support complications for enteral nutrition $(\mathrm{EN})$ and parenteral nutrition (PN) patients 3.1 Analyses by EN - tube feeding and standard care 3.2 Analyses by nutrition status - protein energy malnutrition (PEM) and no PEM 3.3 Analyses by age of population - children and adults

This is a post-peer-review, pre-copyedit version of an article published in Supportive Care in Cancer. The final authenticated version is available online at: https://doi.org/10.1007/s00520-019-05145-w 
March 25, 2019

Study name

\begin{tabular}{|c|c|c|c|c|c|}
\hline & ii & Lower & Upper & Value & Val \\
\hline Thompson et al 1980 & 1.074 & 0.797 & 1.446 & 0.469 & 0.63 \\
\hline Sako et al 1981 & 1.062 & 0.901 & 1.252 & 0.715 & 0.475 \\
\hline Lim et al 1981 & 1.068 & 0.926 & 1.232 & 0.908 & 0.364 \\
\hline Muller et al 1982 & 1.053 & 0.942 & 1.178 & 0.912 & 0.362 \\
\hline Ghavimi et al 1982 & 1.060 & 0.953 & 1.180 & 1.077 & 0.281 \\
\hline Donaldson et al 1982 & 1.062 & 0.954 & 1.181 & 1.099 & 0.272 \\
\hline Hamaoui et al 1990 & 1.060 & 0.957 & 1.174 & 1.113 & 0.266 \\
\hline Von Meyenfeldt et al 1992 & 1.055 & 0.965 & 1.154 & 1.176 & 0.240 \\
\hline Smith et al 1992 & 1.059 & 0.970 & 1.157 & 1.285 & 0.199 \\
\hline Sandstrom et al 1993 & 1.052 & 0.972 & 1.139 & 1.258 & 0.208 \\
\hline Iovinelli et al 1993 & 1.070 & 0.991 & 1.156 & 1.733 & 0.083 \\
\hline Brennan et al 1994 & 1.065 & 0.992 & 1.143 & 1.735 & 0.083 \\
\hline Reynolds et al 1997 & 1.048 & 0.980 & 1.121 & 1.366 & 0.172 \\
\hline Bozzetti et al 2001 & 1.018 & 0.955 & 1.085 & 0.544 & 0.587 \\
\hline Kamei et al 2005 & 1.014 & 0.952 & 1.079 & 0.429 & 0.668 \\
\hline Liu et al 2011 & 1.015 & 0.956 & 1.078 & 0.498 & 0.618 \\
\hline Park et al 2012 & 1.006 & 0.949 & 1.067 & 0.197 & 0.843 \\
\hline Li et al 2015 & 1.011 & 0.956 & 1.071 & 0.392 & 0.695 \\
\hline \multirow{2}{*}{ Huang et al 2015} & 0.999 & 0.945 & 1.057 & -0.034 & 0.973 \\
\hline & 0.999 & 0.945 & 1.057 & -0.034 & 0.973 \\
\hline
\end{tabular}

Cumulative mh risk ratio (95\% CI)

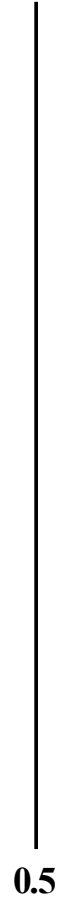

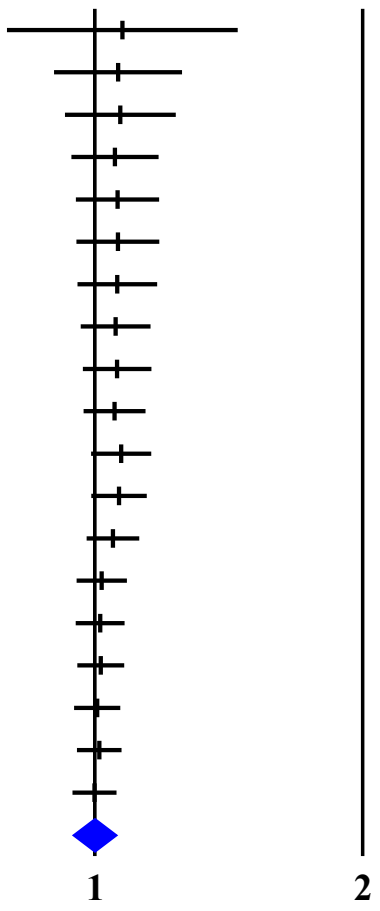

Favours EN

Figure 4. No nutrition support complications for enteral (EN) and parenteral nutrition (PN) patients, over time 
March 25, 2019

Figure 5.1

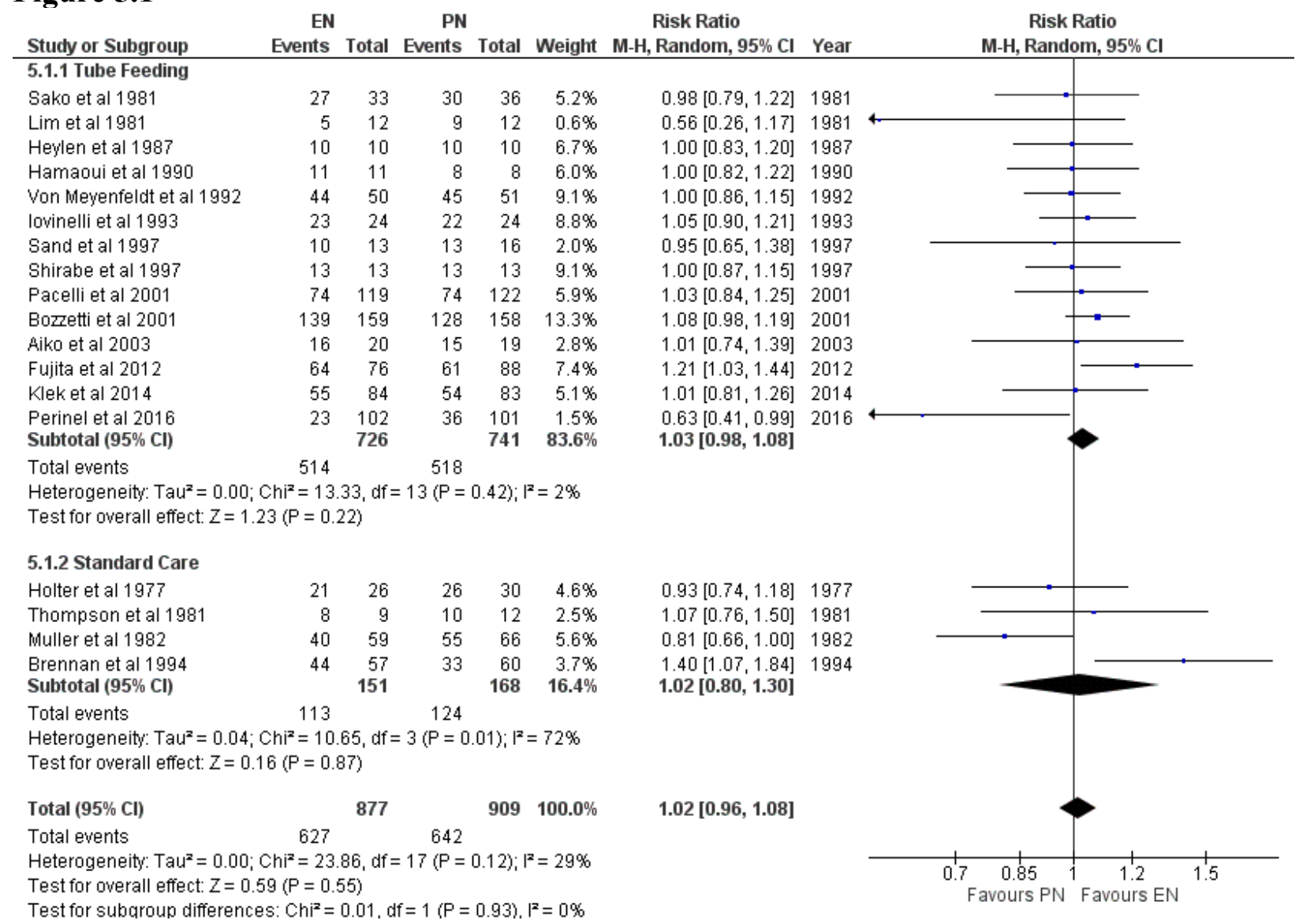

This is a post-peer-review, pre-copyedit version of an article published in Supportive Care in Cancer. The final authenticated version is available online at: https://doi.org/10.1007/s00520-019-05145-w 
March 25, 2019

\section{Figure 5.2}

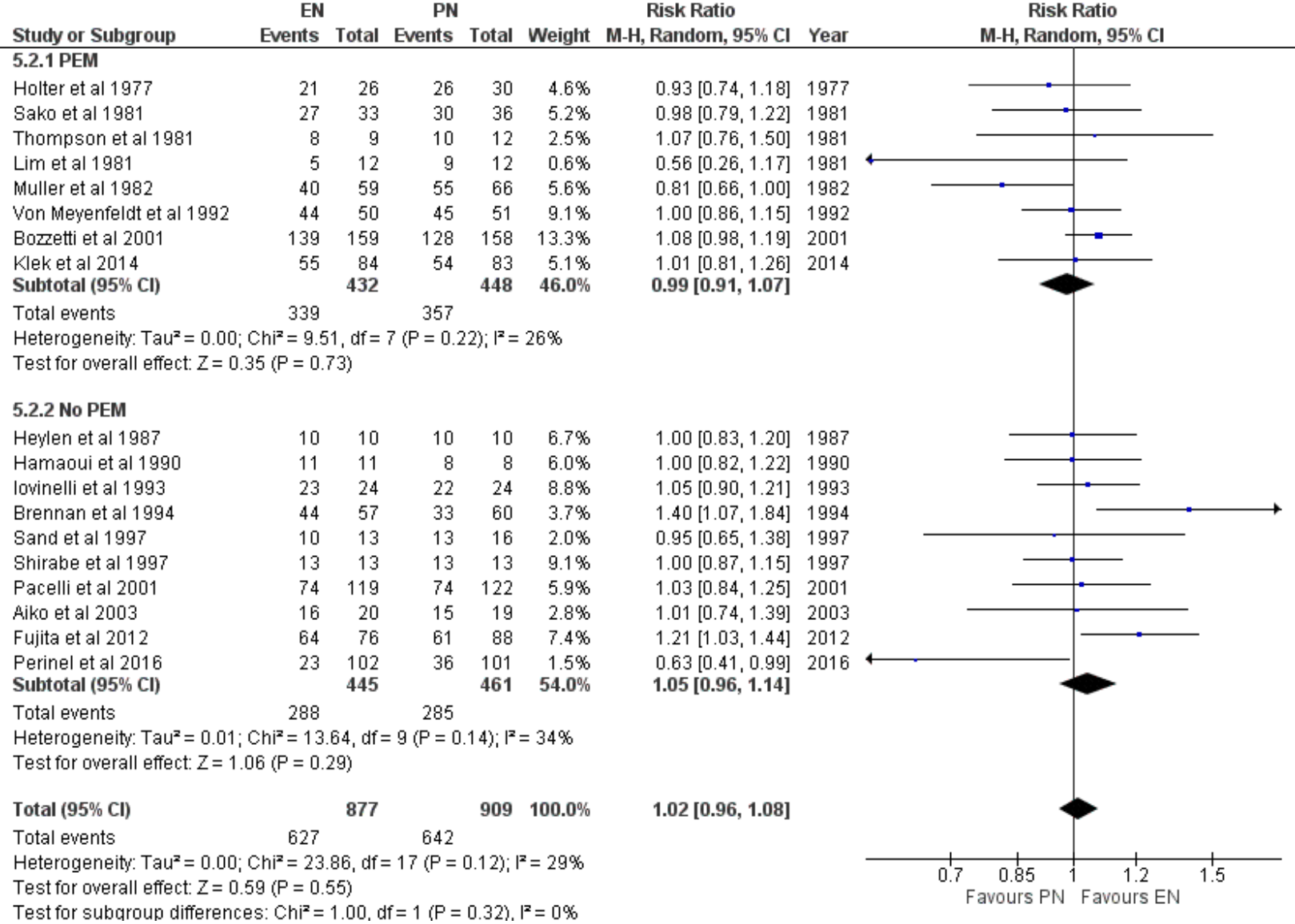

This is a post-peer-review, pre-copyedit version of an article published in Supportive Care in Cancer. The final authenticated version is available online at: https://doi.org/10.1007/s00520-019-05145-w 
March 25, 2019

Figure 5.3

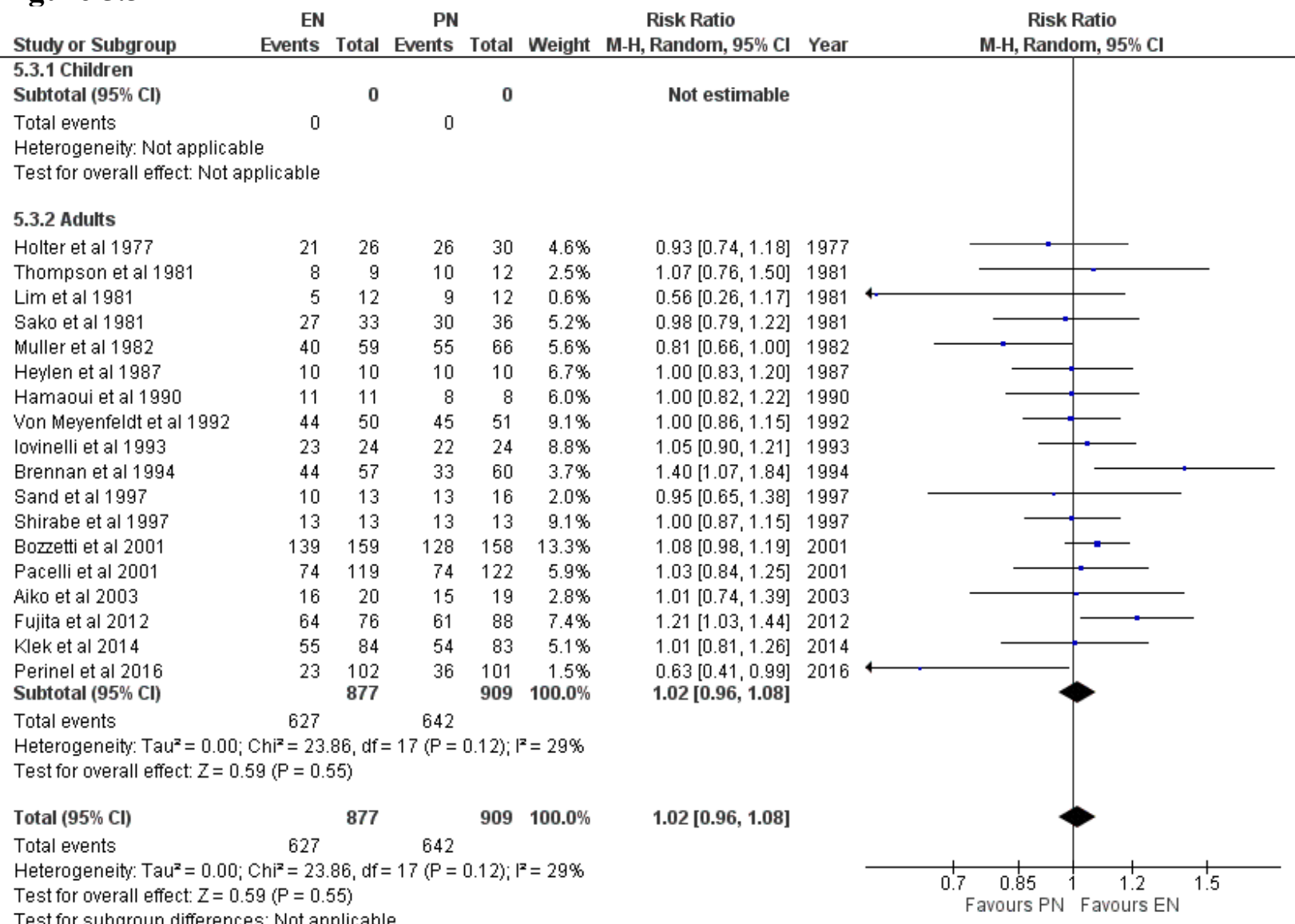

Figure 5. No major complications for enteral nutrition $(\mathrm{EN})$ and parenteral nutrition $(\mathrm{PN})$ patients 5.1 Analyses by EN - tube feeding and standard care 5.2 Analyses by nutrition status - protein energy malnutrition (PEM) and no PEM 5.3 Analyses by age of population - children and adults

This is a post-peer-review, pre-copyedit version of an article published in Supportive Care in Cancer. The final authenticated version is available online at: https://doi.org/10.1007/s00520-019-05145-w 
March 25, 2019

Study name

Holter et al 1977

Thompson et al 1981

Sako et al 1981

Lim et al 1981

Muller et al 1982

Von Meyenfeldt et al 1992

Iovinelli et al 1993

Brennan et al 1994

Sand et al 1997

Bozzetti et al 2001

Pacelli et al 2001

Aiko et al 2003

Fujita et al 2012

Klek et al 2014

Perinel et al 2016
Cumulative statistics

Lower Upper

Point limit limit Z-Value p-Value

$\begin{array}{lllll}0.932 & 0.698 & 1.244 & -0.478 & 0.632\end{array}$

$\begin{array}{lllll}0.979 & 0.777 & 1.232 & -0.182 & 0.856\end{array}$

$\begin{array}{lllll}0.980 & 0.821 & 1.169 & -0.223 & 0.823\end{array}$

$\begin{array}{lllll}0.952 & 0.802 & 1.131 & -0.557 & 0.577\end{array}$

$\begin{array}{lllll}0.909 & 0.787 & 1.051 & -1.291 & 0.197\end{array}$

$\begin{array}{lllll}0.935 & 0.828 & 1.055 & -1.094 & 0.274\end{array}$

$\begin{array}{lllll}0.959 & 0.862 & 1.066 & -0.777 & 0.437\end{array}$

$\begin{array}{lllll}0.996 & 0.901 & 1.102 & -0.071 & 0.943\end{array}$

$\begin{array}{lllll}0.994 & 0.901 & 1.096 & -0.130 & 0.897\end{array}$

$\begin{array}{lllll}1.010 & 0.926 & 1.103 & 0.231 & 0.818\end{array}$

$\begin{array}{lllll}1.012 & 0.931 & 1.099 & 0.278 & 0.781\end{array}$

$\begin{array}{lllll}1.012 & 0.933 & 1.097 & 0.287 & 0.774\end{array}$

$\begin{array}{lllll}1.031 & 0.955 & 1.113 & 0.782 & 0.434\end{array}$

$\begin{array}{lllll}1.029 & 0.956 & 1.108 & 0.766 & 0.444\end{array}$

$\begin{array}{lllll}1.018 & 0.946 & 1.095 & 0.467 & 0.640\end{array}$

$\begin{array}{lllll}1.018 & 0.946 & 1.095 & 0.467 & 0.640\end{array}$
Cumulative mh risk ratio ( $95 \% \mathrm{CI}$ ) $\mid$

0.5

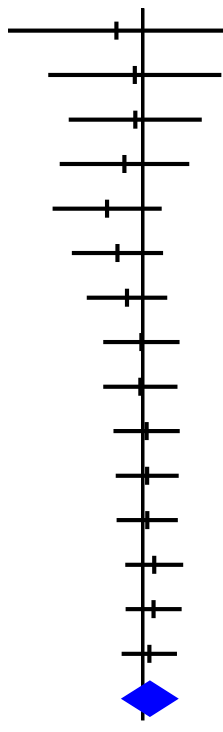

1

Figure 6. No major complications for enteral (EN) and parenteral nutrition (PN) patients, over time 
March 25, 2019

Figure 7.1

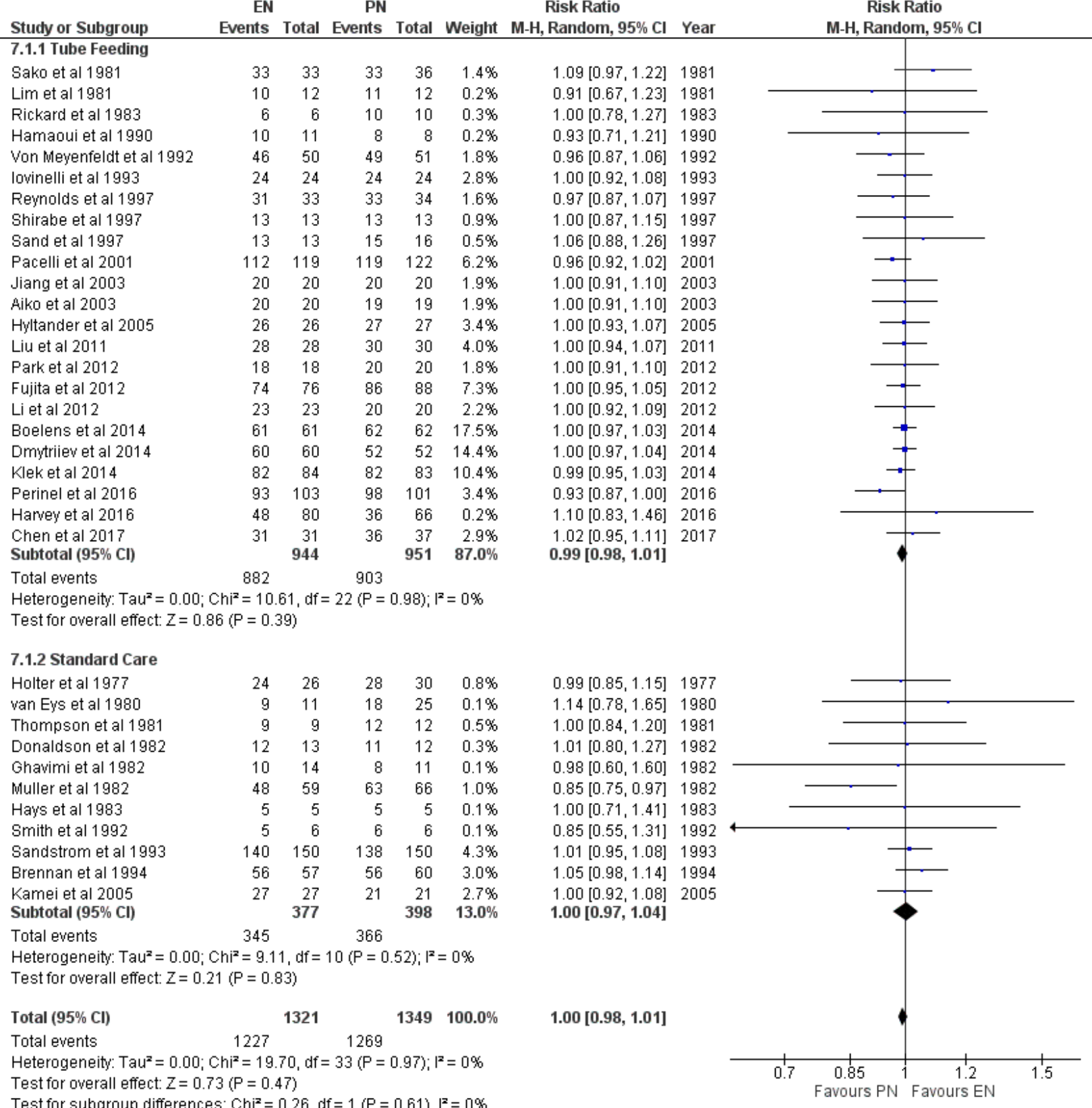

This is a post-peer-review, pre-copyedit version of an article published in Supportive Care in Cancer. The final authenticated version is available online at: https://doi.org/10.1007/s00520-019-05145-w 
March 25, 2019

Figure 7.2

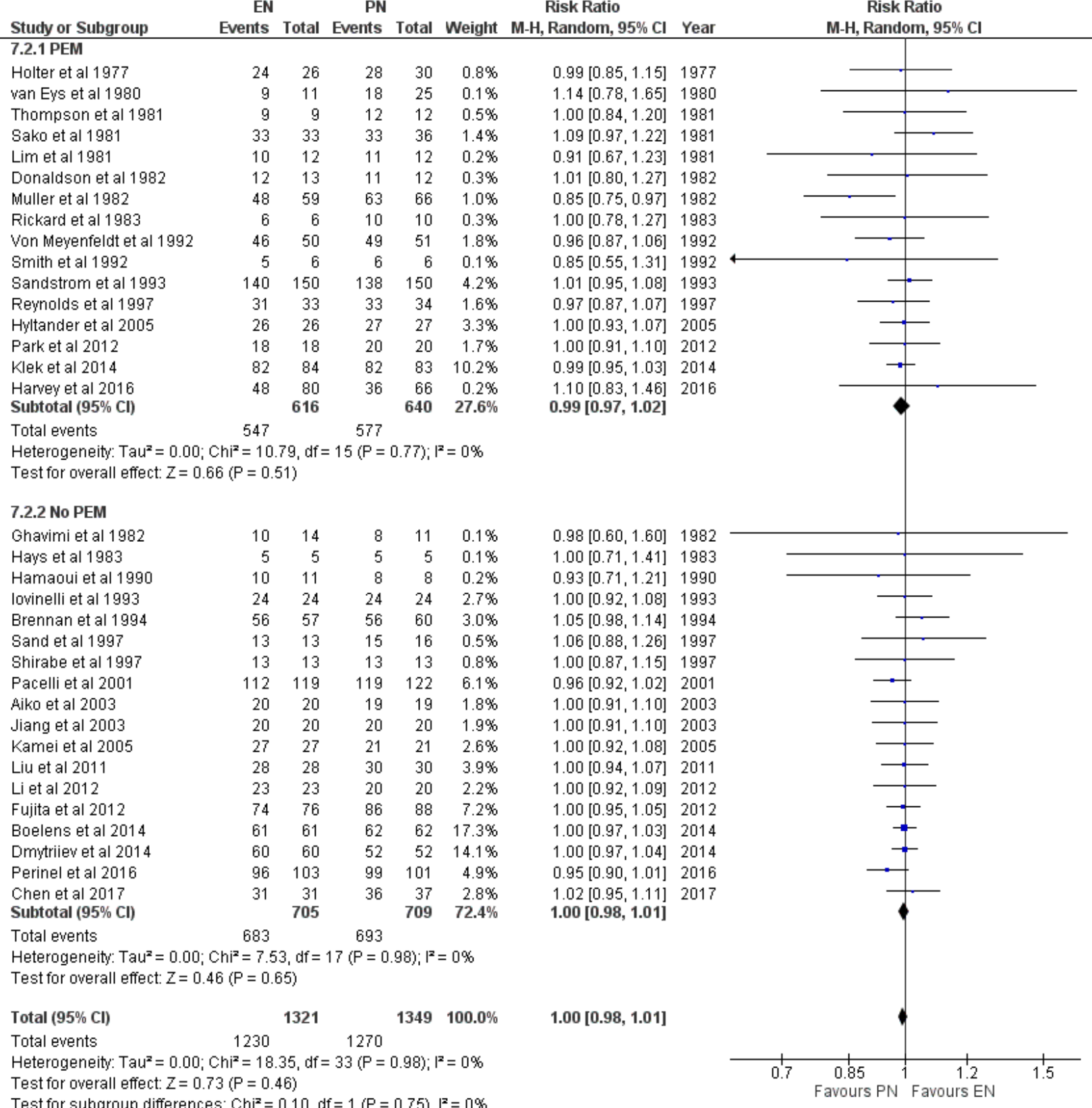

This is a post-peer-review, pre-copyedit version of an article published in Supportive Care in Cancer. The final authenticated version is available online at: https://doi.org/10.1007/s00520-019-05145-w 
March 25, 2019

\section{Figure 7.3}

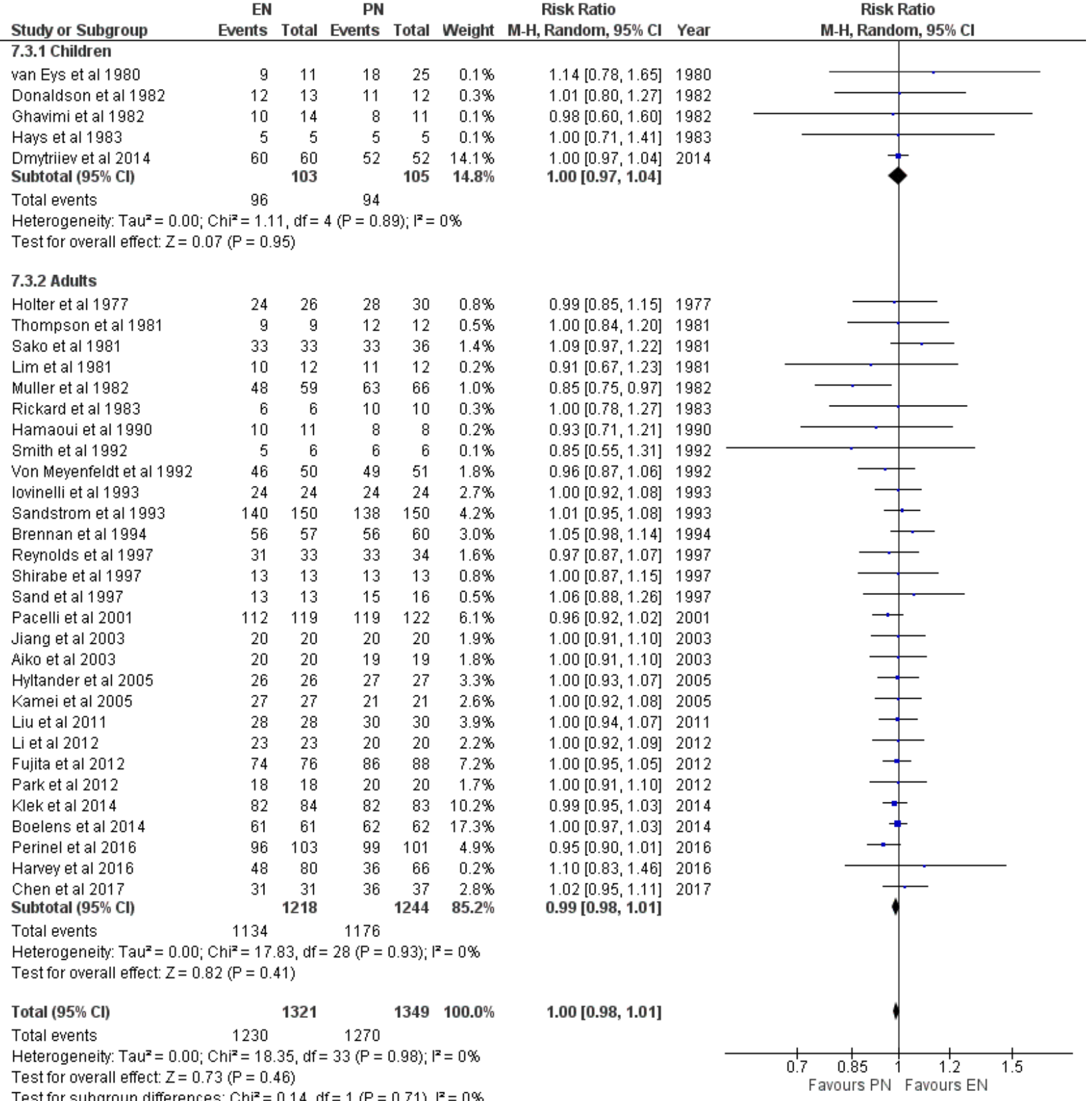

Figure 7. No mortality for enteral nutrition $(\mathrm{EN})$ and parenteral nutrition (PN) patients 7.1 Analyses by EN - tube feeding and standard care 7.2 Analyses by nutrition status - protein energy malnutrition (PEM) and no PEM 7.3 Analyses by age of population - children and adults

This is a post-peer-review, pre-copyedit version of an article published in Supportive Care in Cancer.

The final authenticated version is available online at: https://doi.org/10.1007/s00520-019-05145-w 
March 25, 2019

Study name

Holter et al 1977

van Eys et al 1980

Sako et al 1981

Lim et al 1981

Muller et al 1982

Ghavimi et al 1982

Donaldson et al 1982

Hamaoui et al 1990

Von Meyenfeldt et al 19920.976

Smith et al 1992

Sandstrom et al 1993

Brennan et al 1994

Sand et al 1997

Reynolds et al 1997

Pacelli et al 2001

Fujita et al 2012

Klek et al 2014

Harvey et al 2016

Perinel et al 2016

Chen et al 2017
Cumulative statistics

Lower Upper

Point limit limit Z-Value p-Value

$\begin{array}{lllll}0.989 & 0.854 & 1.145 & -0.148 & 0.882\end{array}$

$\begin{array}{lllll}1.008 & 0.879 & 1.155 & 0.111 & 0.912\end{array}$

$\begin{array}{lllll}1.055 & 0.968 & 1.150 & 1.214 & 0.225\end{array}$

$\begin{array}{lllll}1.043 & 0.960 & 1.134 & 1.001 & 0.317\end{array}$

$\begin{array}{lllll}0.986 & 0.919 & 1.058 & -0.400 & 0.689\end{array}$

$\begin{array}{lllll}0.986 & 0.919 & 1.057 & -0.406 & 0.684\end{array}$

$\begin{array}{lllll}0.987 & 0.924 & 1.056 & -0.372 & 0.710\end{array}$

$\begin{array}{lllll}0.984 & 0.922 & 1.050 & -0.498 & 0.619\end{array}$

$\begin{array}{lllll}0.974 & 0.923 & 1.027 & -0.974 & 0.330\end{array}$

$\begin{array}{lllll}0.990 & 0.951 & 1.032 & -0.458 & 0.647\end{array}$

$\begin{array}{lllll}1.004 & 0.969 & 1.041 & 0.226 & 0.821\end{array}$

$\begin{array}{lllll}1.006 & 0.971 & 1.043 & 0.343 & 0.731\end{array}$

$\begin{array}{lllll}1.002 & 0.969 & 1.036 & 0.128 & 0.898\end{array}$

$\begin{array}{lllll}0.991 & 0.964 & 1.020 & -0.598 & 0.550\end{array}$

$\begin{array}{lllll}0.993 & 0.969 & 1.017 & -0.591 & 0.554\end{array}$

$\begin{array}{lllll}0.991 & 0.971 & 1.013 & -0.801 & 0.423\end{array}$

$\begin{array}{lllll}0.992 & 0.971 & 1.013 & -0.750 & 0.453\end{array}$

$\begin{array}{lllll}0.987 & 0.967 & 1.007 & -1.270 & 0.204\end{array}$

$\begin{array}{lllll}0.989 & 0.970 & 1.009 & -1.074 & 0.283\end{array}$

$\begin{array}{lllll}0.989 & 0.970 & 1.009 & -1.074 & 0.283\end{array}$
Cumulative mh risk ratio $(95 \% \mathrm{CI})$

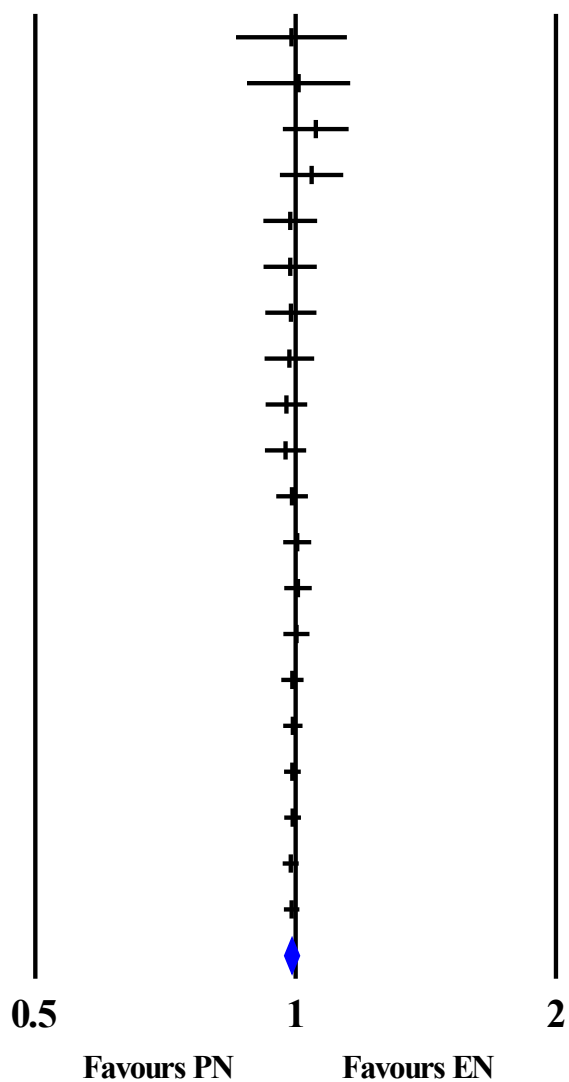

Figure 8. No mortality for enteral (EN) and parenteral nutrition $(\mathrm{PN})$ patients, over time 


\section{Appendix 1. Search Strategy}

Database: Ovid MEDLINE(R) and Epub Ahead of Print, In-Process \& Other Non-Indexed Citations, Daily and Versions(R) $<1946$ to December 20, 2018> Search Strategy:

1 exp Parenteral Nutrition/ (23169)

$2 \exp$ Enteral Nutrition/ (18501)

3 ((parenteral or intravenous*) adj2 (nutrition or feeding)).mp. (31068)

4 ((enteral or enteric or tube or force) adj2 (nutrition or feeding)).mp. (26309)

5 (1 or 3$)$ and (2 or 4$)(6209)$

6 exp Comparative Study/ (1815838)

7 (comparison or comparative or compare* or versus or vs or match or rival* or oppose or "side by side" or alone or prefer* or better).mp. (6846615)

8 or/6-7 (6846615)

95 and $8(2502)$

10 limit 9 to english language (2120)

11 limit 10 to randomized controlled trial (288)

$* * * * * * * * * * * * * * * * * * * * * * * * * * *$

Database: Embase Classic+Embase <1947 to 2018 Week 51> Search Strategy:

1 exp parenteral nutrition/ (47926)

2 exp enteric feeding/ (29141)

3 ((parenteral or intravenous*) adj2 (nutrition or feeding)).mp. (49280)

4 ((enteral or enteric or tube or force) adj2 (nutrition or feeding)).mp. (41156)

5 (1 or 3$)$ and $(2$ or 4$)(10801)$

6 exp comparative study/ (1327146)

7 (comparison or comparative or compare* or versus or vs or match or rival* or oppose or "side by side" or alone or prefer* or better).mp. (9108614)

8 or/6-7 (9108614)

95 and 8 (4130)

10 limit 9 to english language (3499)

11 limit 10 to randomized controlled trial (402)

*****************************

Database: EBM Reviews - Cochrane Central Register of Controlled Trials $<$ November 2018 $>$ Search Strategy:

1 exp Parenteral Nutrition/ (1554)

2 exp Enteral Nutrition/ (1644)

3 ((parenteral or intravenous*) adj2 (nutrition or feeding)).mp. (4161)

4 ((enteral or enteric or tube or force) adj2 (nutrition or feeding)).mp. (4659)

5 (1 or 3$)$ and (2 or 4$)(1653)$

6 exp Comparative Study/ (11) 
March 25, 2019

7 (comparison or comparative or compare* or versus or vs or match or rival* or oppose or "side by side" or alone or prefer* or better).mp. (732365)

8 or/6-7 (732365)

95 and $8(826)$

10 limit 9 to english language (545)

$* * * * * * * * * * * * * * * * * * * * * * * * * * *$ 
March 25, 2019

\section{Appendix 2. PRISMA Flow Diagram}

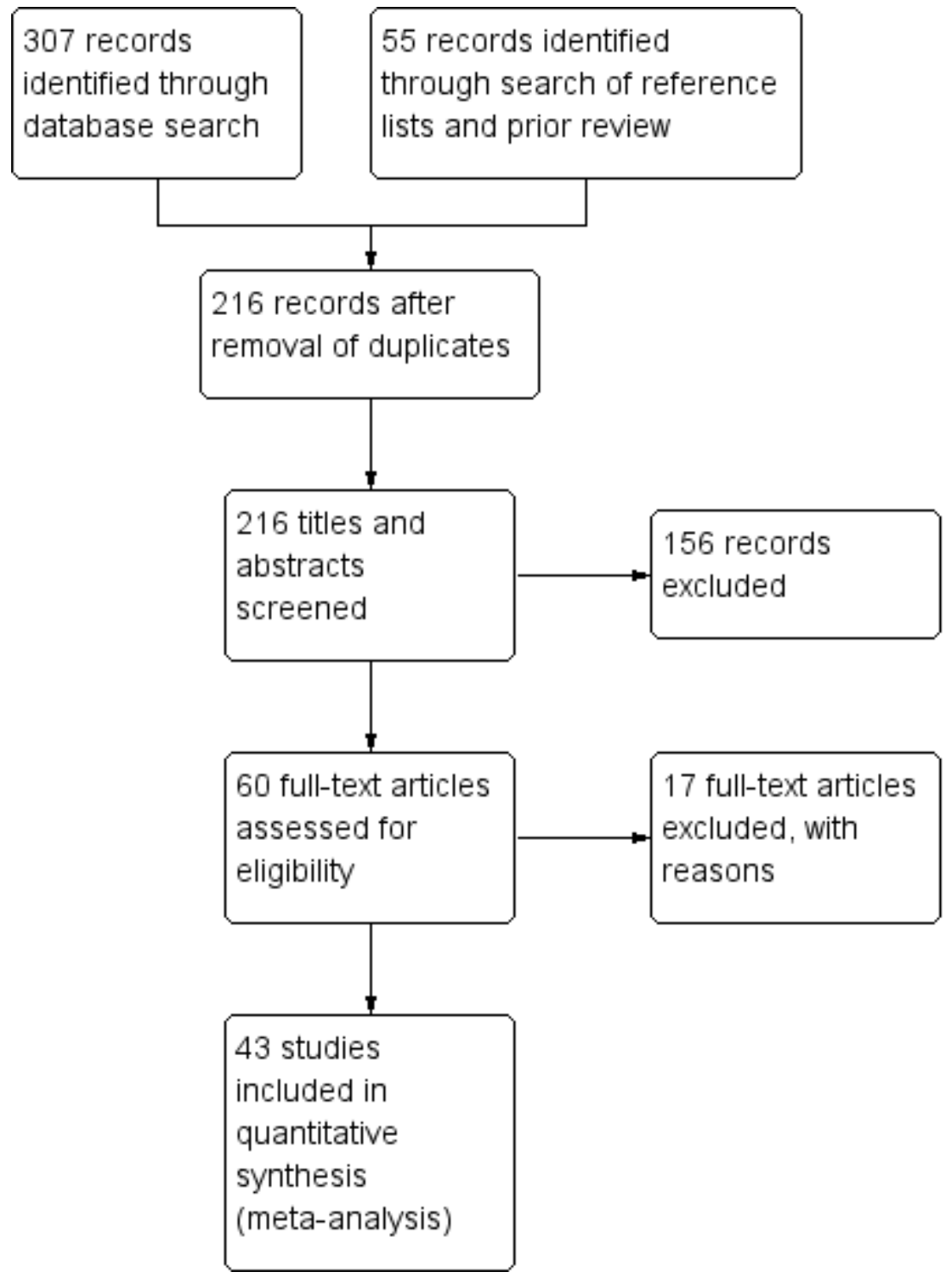

This is a post-peer-review, pre-copyedit version of an article published in Supportive Care in Cancer. The final authenticated version is available online at: https://doi.org/10.1007/s00520-019-05145-w 
March 25, 2019

Appendix 3. Assessment of risk of bias

Random sequence generation (selection bias)

Allocation concealment (selection bias)

Blinding of participants and personnel (performance bias)

Blinding of outcome assessment (detection bias)

Incomplete outcome data (attrition bias)

Selective reporting (reporting bias)

Other bias

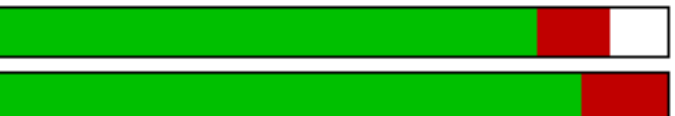

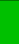
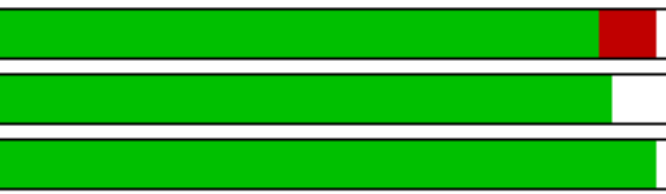

$+$

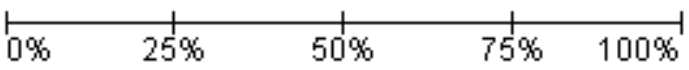

Low risk of bias

Unclear risk of bias

High risk of bias

This is a post-peer-review, pre-copyedit version of an article published in Supportive Care in Cancer.

The final authenticated version is available online at: https://doi.org/10.1007/s00520-019-05145-w 
March 25, 2019

\section{Appendix 4.1}

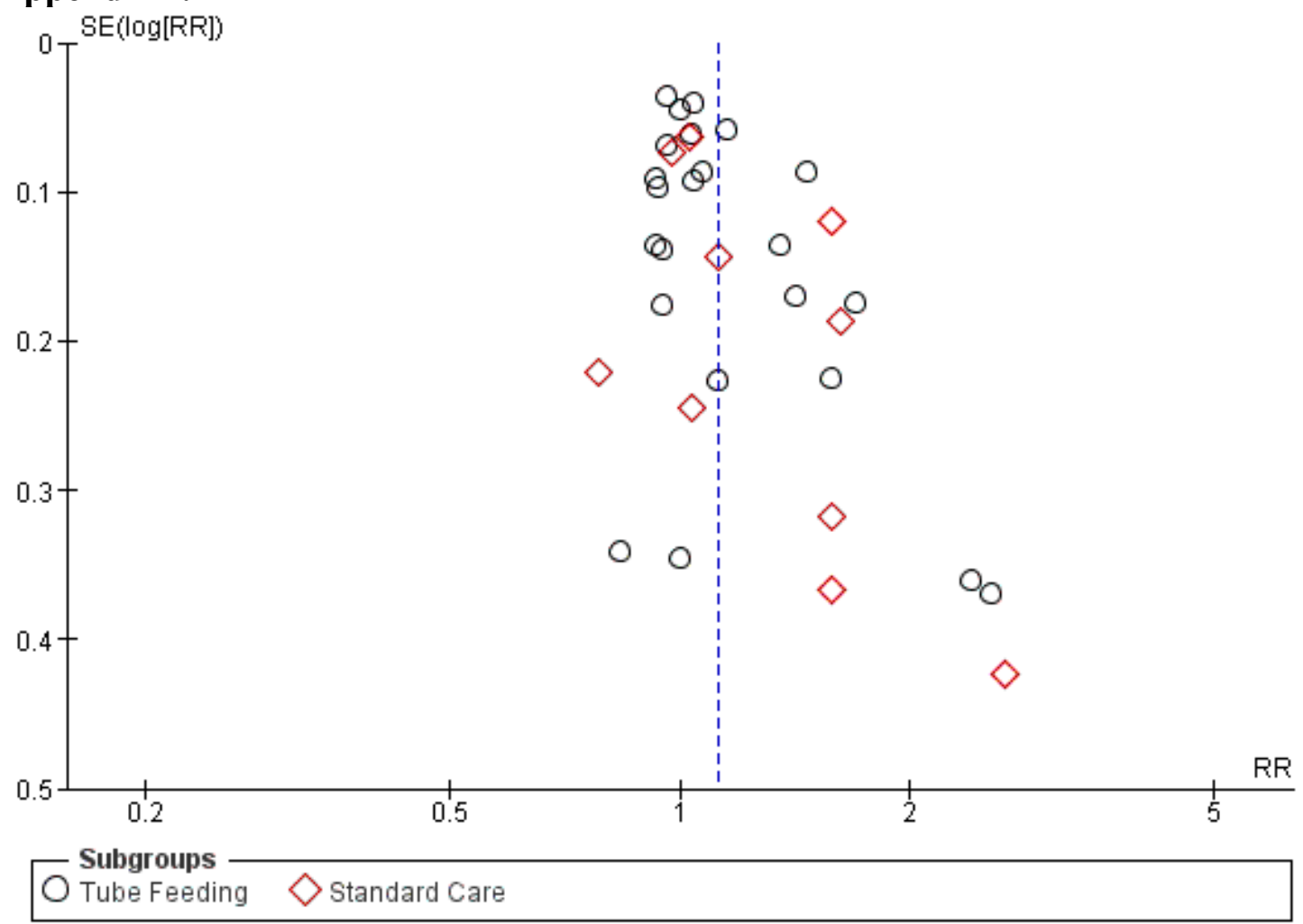

\section{Appendix 4.2}

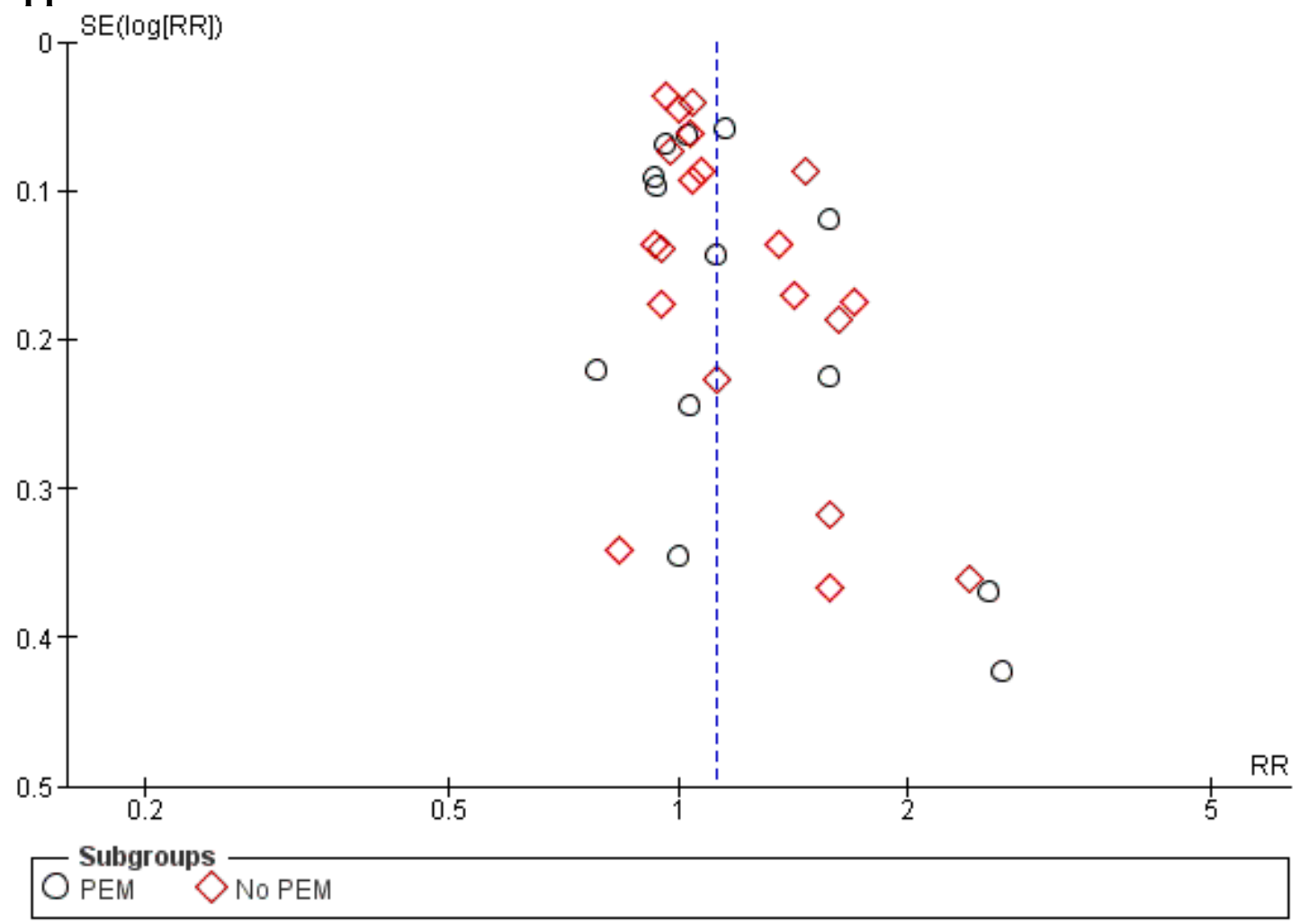

This is a post-peer-review, pre-copyedit version of an article published in Supportive Care in Cancer. The final authenticated version is available online at: https://doi.org/10.1007/s00520-019-05145-w 


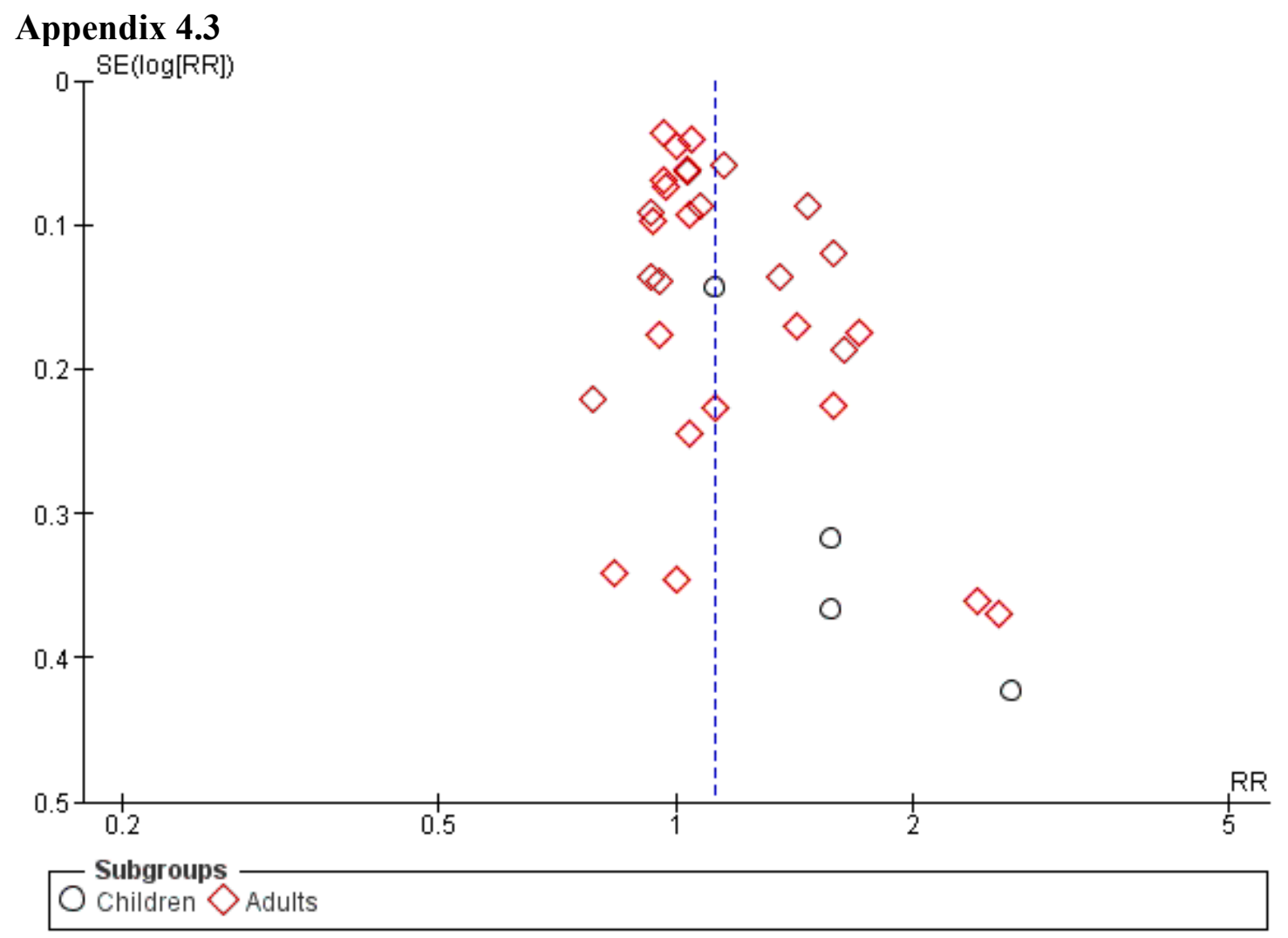

Appendix 4. Assessment of publication bias for endpoint "No infection" 4.1 Assessment by enteral nutrition (EN) - tube feeding and standard care 4.2 Assessment by nutrition status - protein energy malnutrition (PEM) and PEM 4.3 Assessment by age of population - children and adults 
March 25, 2019

\section{Appendix 5.1}

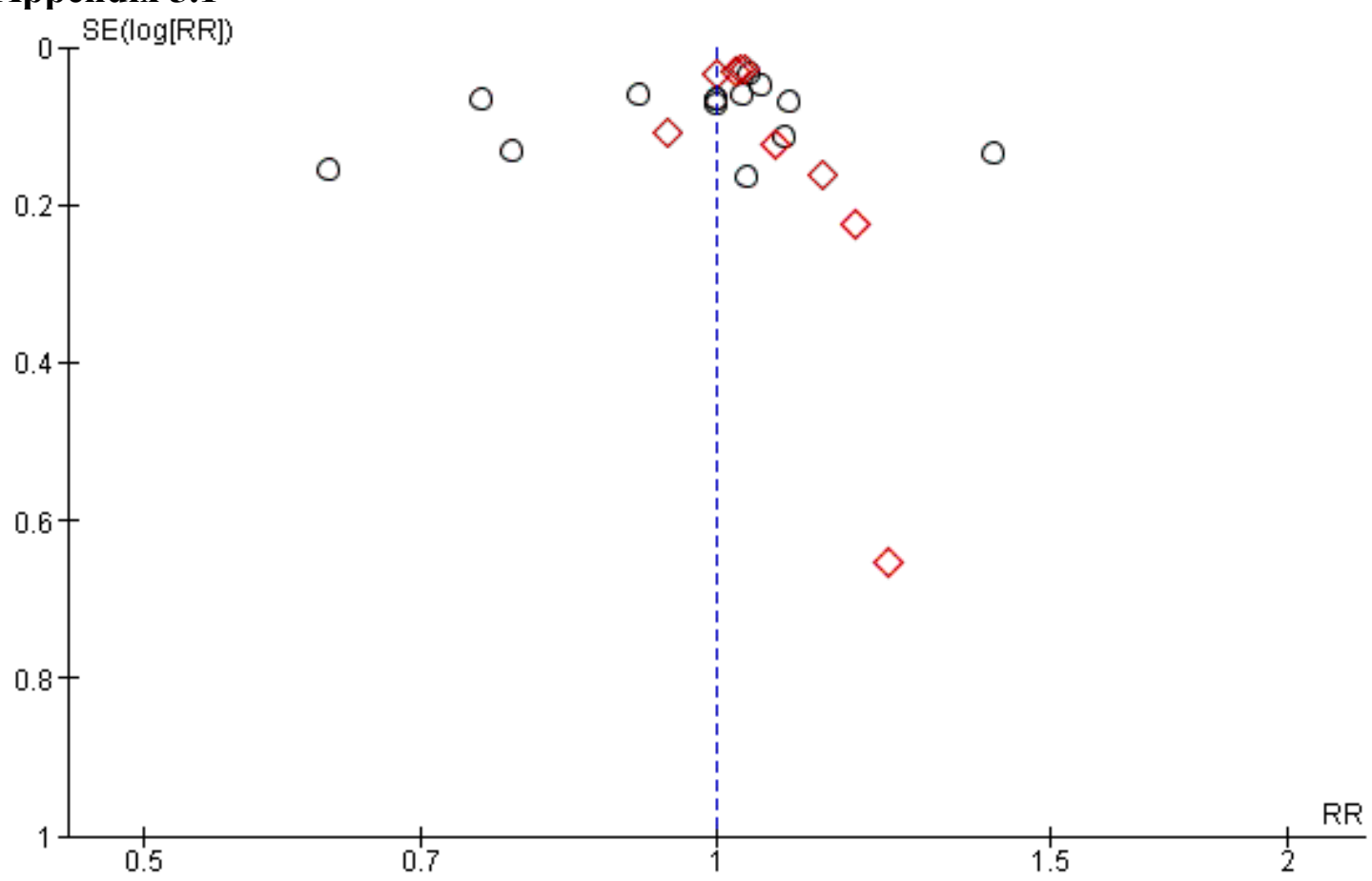

Subgroups

Tube Feeding $\diamond$ Standard Care

\section{Appendix 5.2}

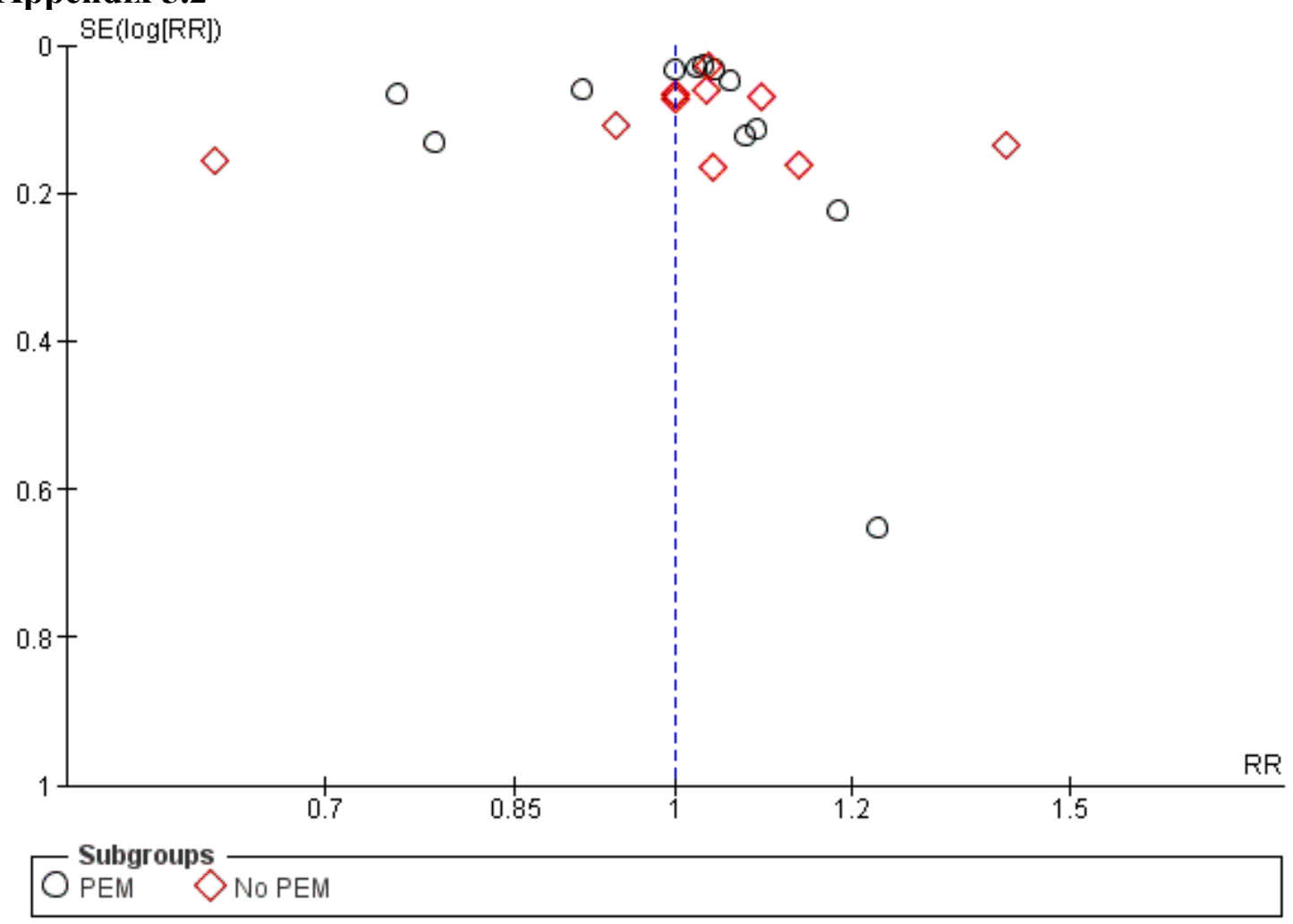

This is a post-peer-review, pre-copyedit version of an article published in Supportive Care in Cancer. The final authenticated version is available online at: https://doi.org/10.1007/s00520-019-05145-w 
March 25, 2019

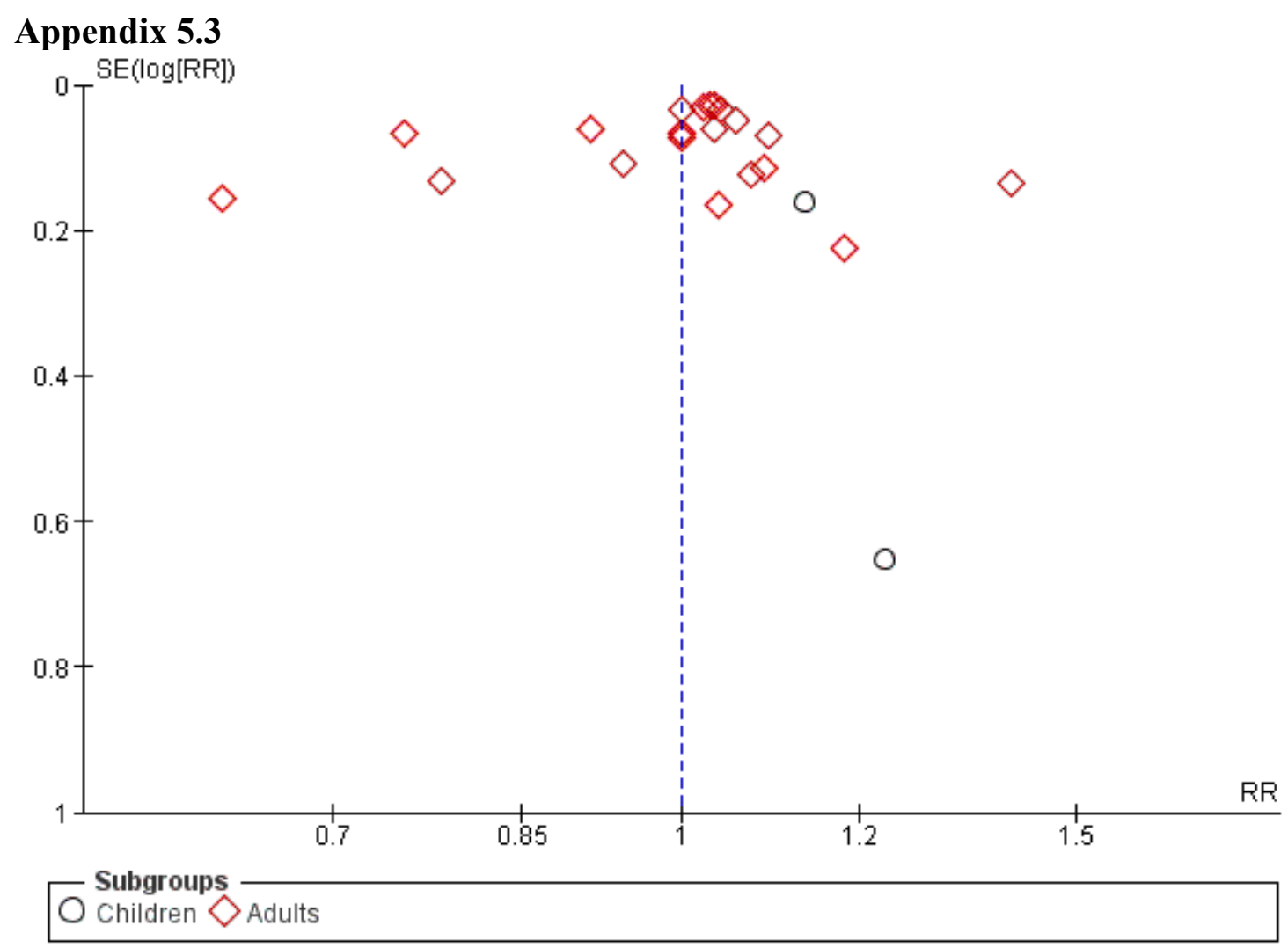

Appendix 5. Assessment of publication bias for endpoint "No nutrition support complications" 5.1 Assessment by enteral nutrition (EN) - tube feeding and standard care 5.2 Assessment by nutrition status - protein energy malnutrition (PEM) and PEM 5.3 Assessment by age of population - children and adults 
March 25, 2019

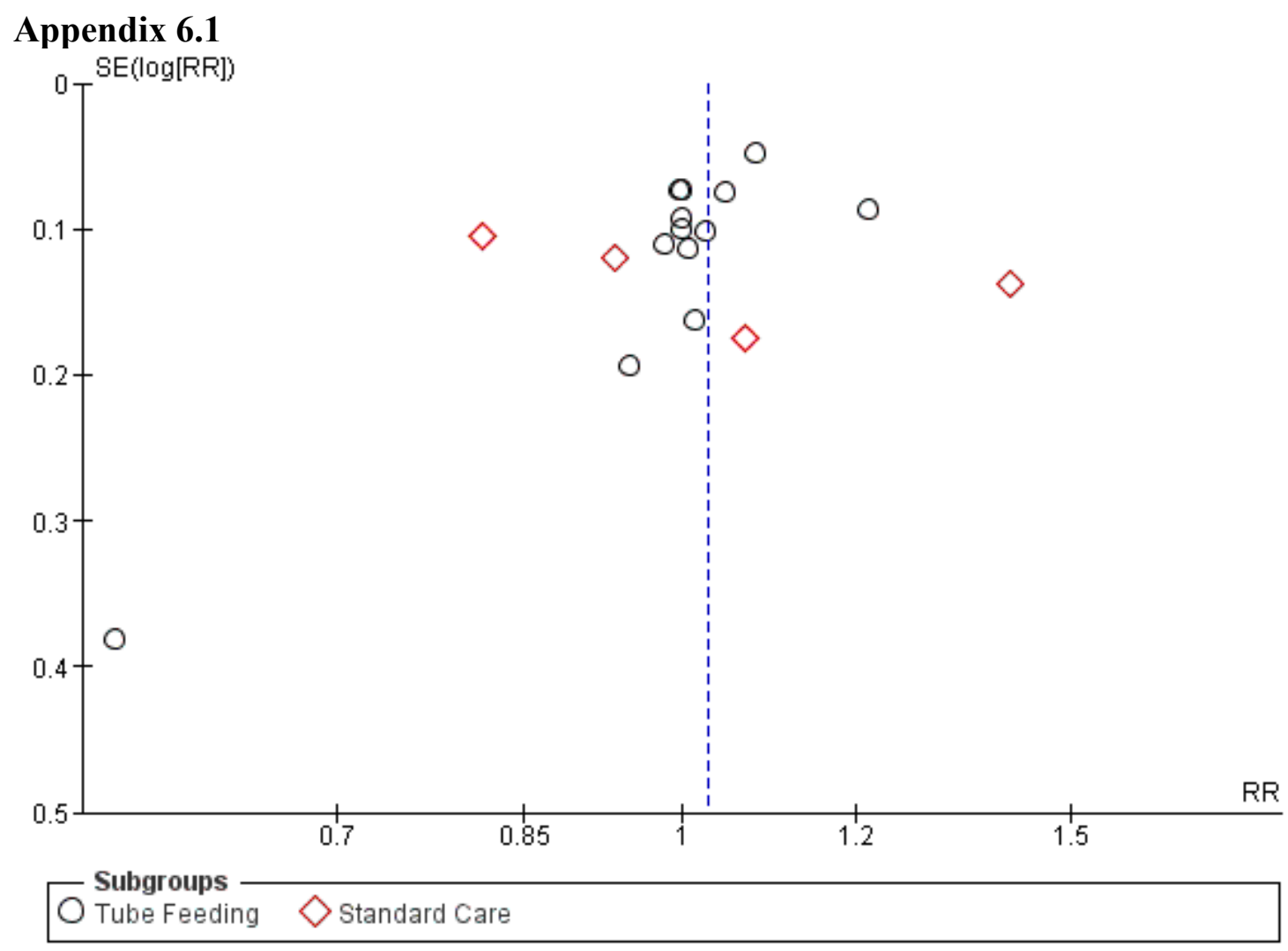

\section{Appendix 6.2}

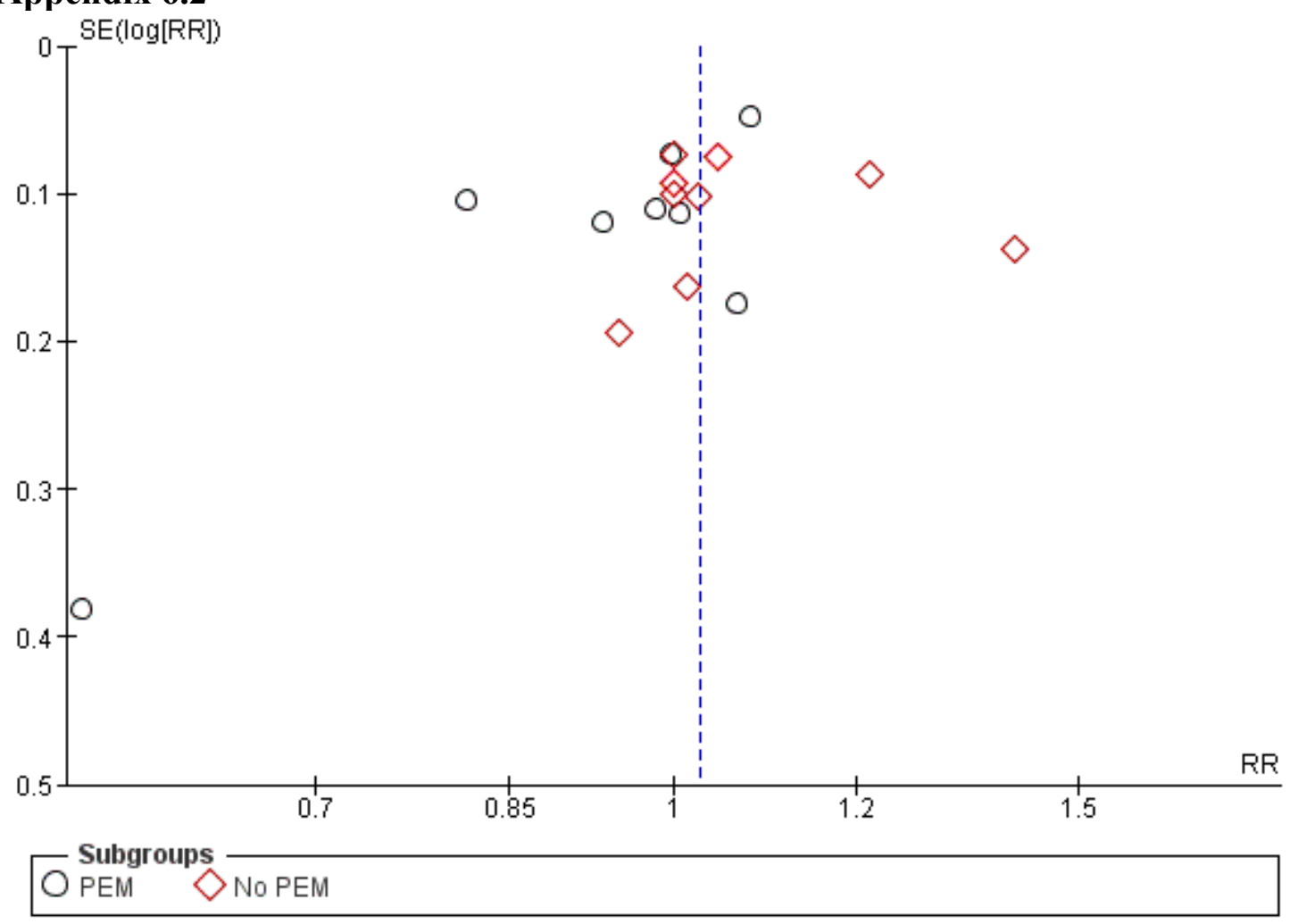

This is a post-peer-review, pre-copyedit version of an article published in Supportive Care in Cancer. The final authenticated version is available online at: https://doi.org/10.1007/s00520-019-05145-w 
March 25, 2019

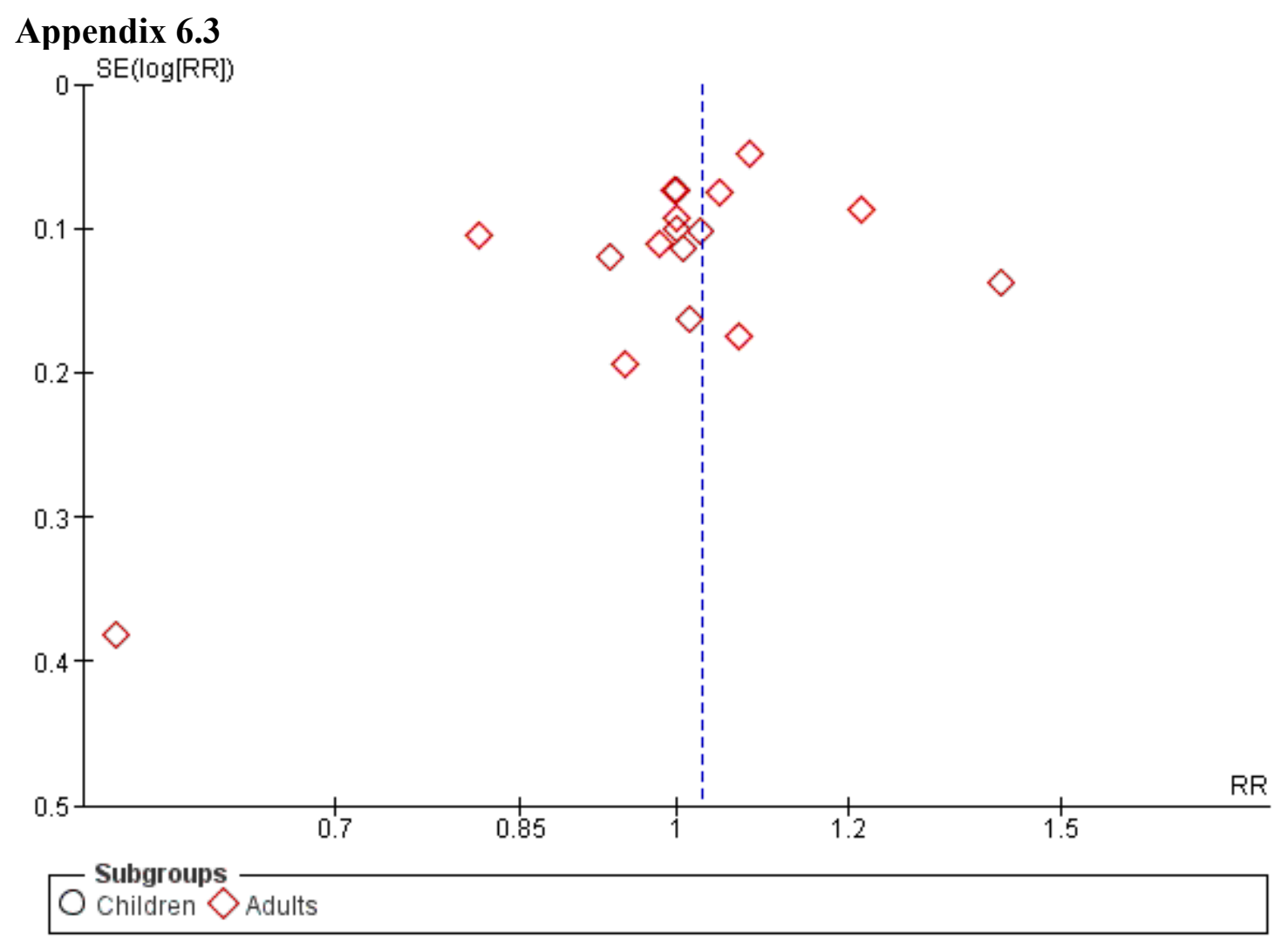

Appendix 6. Assessment of publication bias for endpoint "No major complications" 6.1 Assessment by enteral nutrition (EN) - tube feeding and standard care 6.2 Assessment by nutrition status - protein energy malnutrition (PEM) and PEM 6.3 Assessment by age of population children and adults 
March 25, 2019

\section{Appendix 7.1}

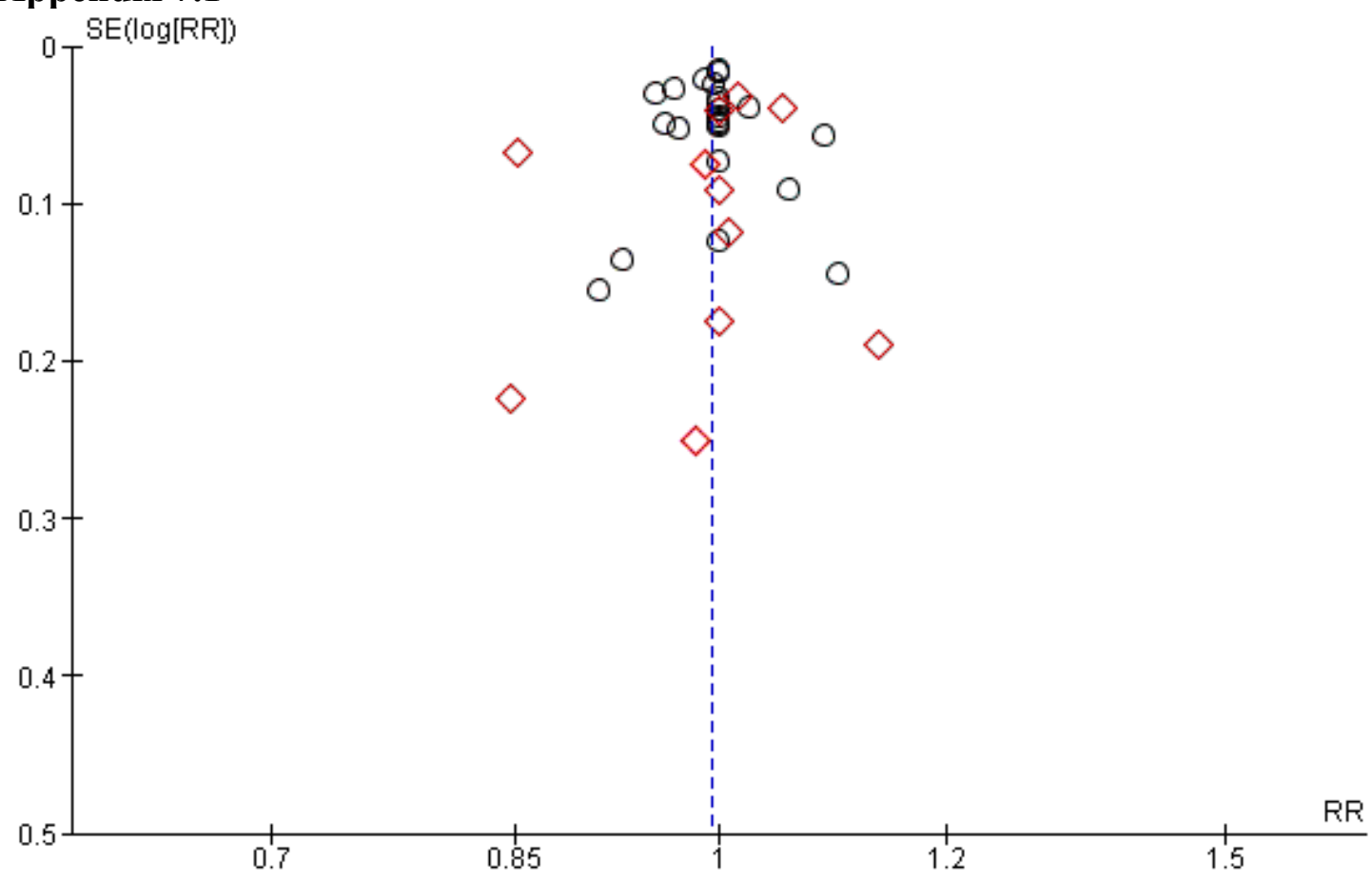

Subgroups

Tube Feeding $\diamond$ Standard Care

\section{Appendix 7.2}

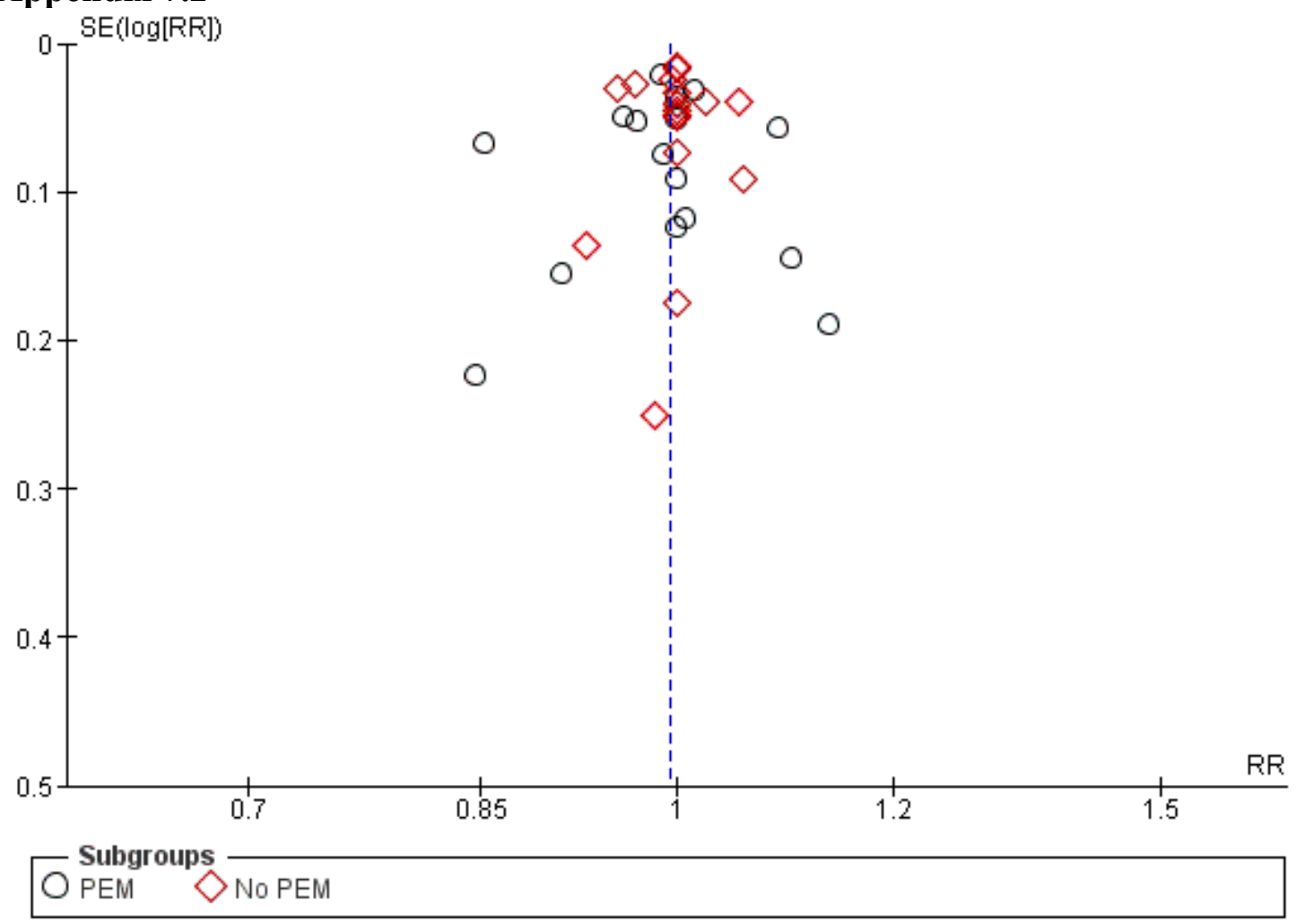

This is a post-peer-review, pre-copyedit version of an article published in Supportive Care in Cancer. The final authenticated version is available online at: https://doi.org/10.1007/s00520-019-05145-w 


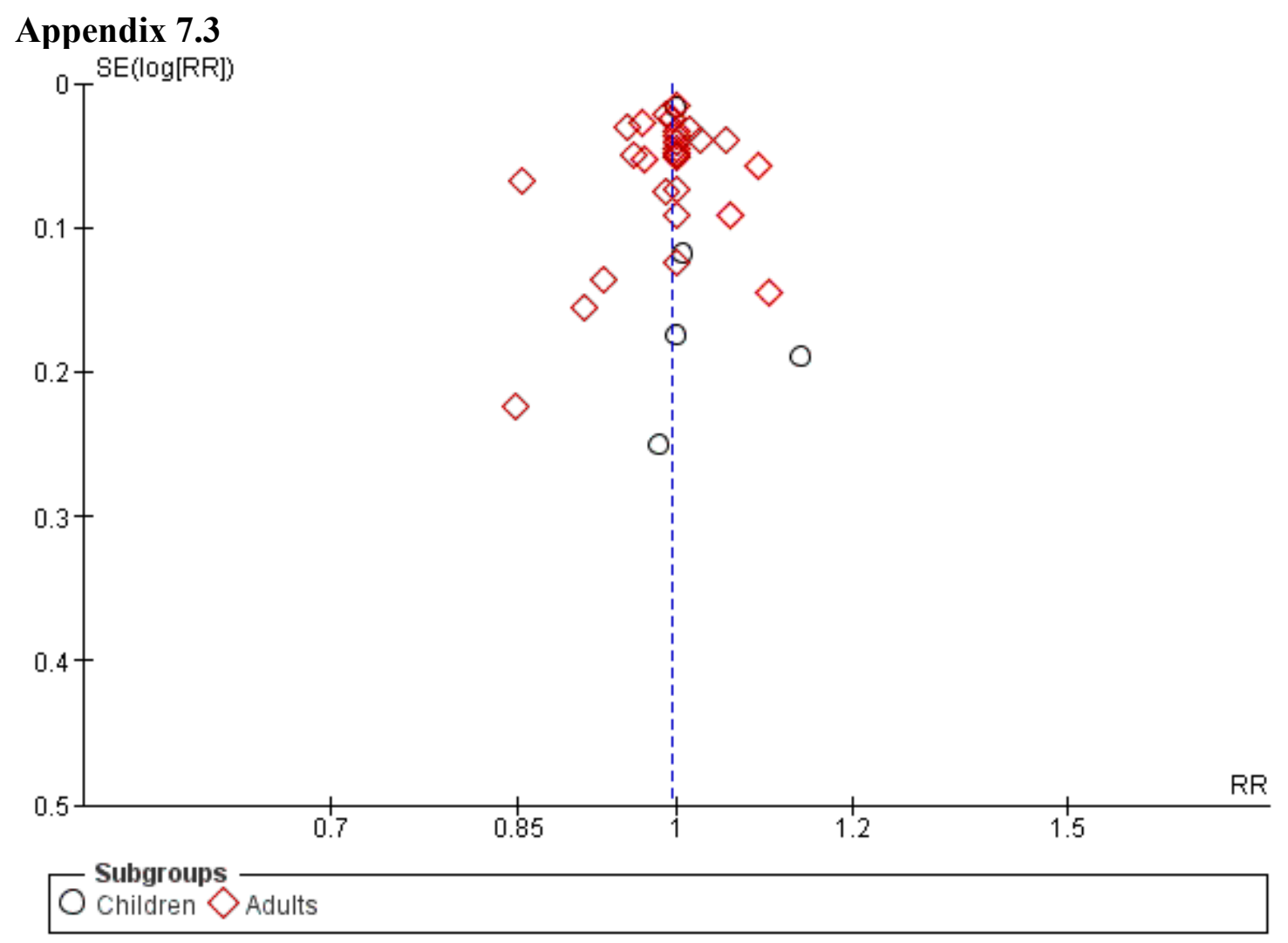

Appendix 7. Assessment of publication bias for endpoint "No mortality" 7.1 Assessment by enteral nutrition (EN) - tube feeding and standard care 7.2 Assessment by nutrition status - protein energy malnutrition (PEM) and PEM 7.3 Assessment by age of population - children and adults 